\title{
Identification of a novel component of the nonsense-mediated mRNA decay pathway by use of an interacting protein screen
}

\author{
Feng He and Allan Jacobson ${ }^{1}$ \\ Department of Molecular Genetics and Microbiology, University of Massachusetts Medical School, Worcester, \\ Massachusetts 01655-0122 USA
}

\begin{abstract}
Rapid turnover of nonsense-containing mRNAs in yeast is dependent on the product of the UPF1 gene (Upf1p). Mutations in UPF1 lead to the selective stabilization of mRNAs containing early nonsense mutations without affecting the decay rates of most other mRNAs. To identify other integral components of this decay pathway, we have employed a two-hybrid screen, seeking those cellular factors that specifically interact with Upf1p. Screening of yeast genomic libraries identified six genes encoding potential Upf1p-interacting proteins. These include four previously uncharacterized genes, NMD1-4 (nonsense-mediated mRNA decay), DBP2, a gene encoding a putative RNA helicase with homology to mammalian p68 RNA helicase, and SNP1, a gene encoding a U1 snRNP 70-kD protein homolog. In this paper we report the identification and characterization of NMD2, a yeast gene that encodes a specific Upf1p-interacting protein. Disruption of NMD2 yields a nonsense-mediated mRNA decay phenotype identical to that obtained in UPF1-deletion strains, indicating that the NMD2 gene product ( $\mathrm{Nmd2p}$ ) is a new factor in the nonsense-mediated mRNA decay pathway. Deletion analysis demonstrated that the acidic carboxyl terminus of Nmd2p constituted the Upf1p-interacting domain. High-level expression of a fragment of Nmd2p containing this domain had a dominant-negative effect on nonsense-mediated mRNA decay when the protein was localized to the cytoplasm but not when it was localized to the nucleus, indicating that this decay pathway has a cytoplasmic component. The association of a dominant-negative phenotype with a gene fragment identified in a two-hybrid screen suggests a generalized approach to confirming the function of genes identified in such screens.
\end{abstract}

[Key Words: mRNA decay; translation; NMD2; Upflp-interacting factors]

Received October 12, 1994; revised version accepted January 4, 1995.

In most genetic systems, 61 of the 64 possible codon triplets encode amino acids, and the triplets UAA, UAG, and UGA are noncoding and promote translational termination (Osawa et al. 1992). Although the polypeptide chain-terminating effects of UAA, UAG, and UGA triplets have been amply documented and characterized (Craigen et al. 1990), they are not the only consequences of the occurrence of nonsense codons. For example, in both prokaryotes and eukaryotes, nonsense mutations in a gene can enhance the decay rate of the mRNA transcribed from that gene, a phenomenon we describe as nonsense-mediated mRNA decay (for review, see Peltz et al. 1994).

Nonsense-mediated mRNA decay has been studied extensively in the yeast Saccharomyces cerevisiae where it has been shown that degradation of mRNA via this pathway is most likely to occur in the cytoplasm and is

${ }^{1}$ Corresponding author. linked to translation. Evidence in support of these conclusions includes the following: (1) Unstable, nonsensecontaining mRNAs are stabilized in a strain harboring an amber suppressor tRNA (Losson and Lacroute 1979; Gozalbo and Hohmann 1990); (2) nonsense-containing mRNAs are ribosome-associated (Leeds et al. 1991; He et al. 1993; S. Zhang, E.M. Welch, K. Hagan, A. Brown, A. Jacobson, and S. Peltz, in prep.), and the number of ribosomes associated with such mRNAs is a function of the relative positions of the respective nonsense codons ( $\mathrm{He}$ et al. 1993); (3) treatment of cells with cycloheximide, an inhibitor of translational elongation, stabilizes nonsense-containing mRNAs yet removal of cycloheximide leads to the immediate restoration of rapid mRNA decay (Peltz et al. 1993; S. Zhang, E.M. Welch, K. Hagan, A. Brown, A. Jacobson, and S. Peltz, in prep.); and (4) decay of nonsense-containing $\mathrm{mRNAs}$ requires, in addition to a nonsense codon, downstream sequences that appear to be a site of translational reinitiation (Peltz et al. 1993, 1994). 
Previous studies of nonsense-mediated mRNA decay in yeast also showed that the products of the UPF1 and UPF3 genes (Upflp and Upf3p) are essential components of this degradative pathway. Mutations in these genes stabilize mRNAs containing premature nonsense codons without affecting the decay rates of most wild-type transcripts (Leeds et al. 1991, 1992; Peltz et al. 1993, 1994; He et al. 1993). The UPF1 gene has been cloned and sequenced and shown to be (1) nonessential for viability; (2) capable of encoding a $109-\mathrm{kD}$ protein with zinc finger, nucleotide binding site, and RNA helicase motifs (Altamura et al. 1992; Koonin 1992; Leeds et al. 1992); (3) identical to NAM7, a nuclear gene that was isolated as a high-copy suppressor of mitochondrial RNA-splicing mutations (Altamura et al. 1992); and (4) partially homologous to the yeast SEN1 gene (Leeds et al. 1992). The latter encodes a noncatalytic subunit of the tRNA splicing endonuclease complex (Winey and Culbertson 1988; DeMarini et al. 1992), suggesting that the UPF1 protein (Upflp) may also be part of a nuclease complex targeted specifically to nonsense-containing mRNAs.

To further understand this decay pathway and the function of Upflp, we sought to identify genes that encode potential Upf1p-interacting proteins. To this end, we have employed the two-hybrid system, which allows detection of protein-protein interactions via the reconstitution of a functional GAL4 transcriptional activator in yeast (Fields and Song 1989; Chien et al. 1991; Fields and Sternglanz 1994). In this paper we report the identification of NMD2 (nonsense-mediated decay), a yeast gene that encodes a specific Upflp-interacting protein. Disruption of $N M D 2$ or overexpression of a carboxy-terminal fragment of the $N M D 2$ protein yields a nonsensemediated mRNA decay phenotype identical to that obtained in UPF1 deletion strains, indicating that the $N M D 2$ gene product $(\mathrm{Nmd} 2 \mathrm{p})$ is a novel component of the nonsense-mediated mRNA decay pathway.

\section{Results \\ Identification of genes encoding putative Upf1p-interacting proteins}

We have used the two-hybrid system to identify genes encoding putative Upflp-interacting proteins. This method of detecting protein-protein interactions in yeast is based on the observation that the DNA-binding and transcriptional activation functions of the GAL4 protein (Gal4p) can reside on two distinct chimeric polypeptides and still activate transcription from a $G A L$ upstream activating sequence (UAS), provided that the two polypeptides can interact with each other (Fields and Song 1989; Chien et al. 1991). As employed here, the first hybrid was encoded by a plasmid in which the entire UPF1-coding region was fused in-frame to the Gal4p DNA-binding domain (amino acids 1-147); second hybrids were encoded by genomic DNA libraries fused, in three separate frames, to sequences encoding the Gal4p transcriptional activation domain /amino acids 768-881). Both were cotransformed into a Saccharomy- ces cerevisiae strain that contained an integrated GAL1lac $Z$ reporter construct, and colonies expressing detectable $\beta$-galactosidase activity were sought.

We screened $\sim 400,000$ transformants. Eighty-seven colonies that demonstrated $\beta$-galactosidase activity (i.e., colonies pale blue to dark blue on X-gal plates) on the initial screen were isolated. Because the libraries were constructed with genomic DNA from a GAL4 wild-type strain, plasmids containing the GAL4 gene, or fragments thereof, are capable of activating transcription of the GAL1-lacZ reporter gene. These false-positive colonies were eliminated by use of the polymerase chain reaction (PCR; White et al. 1989) with GAL4-specific primers. The library plasmids from the remaining colonies were rescued and tested for specificity by retransformation into the original strain with either (1) the GAL4-UPF1 fusion; (2) the GAL4 DNA-binding domain vector only; (3) an unrelated fusion, GAL4-CEP1; or (4) an unrelated fusion, GAL4-LAM5 (Bartel et al. 1993). Forty-two plasmids that yielded blue colonies only with the GAL4UPF1 fusion were characterized further by restriction mapping, Southern analysis, and partial DNA sequence analysis and yielded nine different genes. Six of these encode putative Upflp-interacting proteins because their activity in the assay is dependent on fusion to the GAL4 activation domain. The remaining three do not require the presence of the GAL4 activation domain and are likely to possess their own activation domains and nuclear localization signals; whether these genes encode Upf lp-interacting proteins remains to be established.

Of the six genes encoding putative Upflp-interacting proteins, two are identical to previously characterized yeast genes, that is, $D B P 2$, a gene encoding a putative RNA helicase with homology to the mammalian p68 RNA helicase (Iggo et al. 1991), and SNP1, a gene encoding a Ul small nuclear ribonucleoprotein (snRNP) 70-kD protein homolog (Smith and Barrell 1991). The other four have no apparent homologs in the available data bases, and we have named these genes NMD1-4. In this paper we have focused on the NMD2 gene; characterization of the other genes will be described elsewhere.

\section{Molecular cloning of the NMD2 gene}

As defined by a qualitative $\beta$-galactosidase assay, $\mathrm{Nmd} 2 \mathrm{p}$ showed a specific dependency on Upflp in the two-hybrid system. Cells expressing a GAL4 activation domain-NMD2 fusion demonstrated strong $\beta$-galactosidase activity when simultaneously expressing a GAL4 DNA-binding domain-UPF1 fusion but had no detectable $\beta$-galactosidase activity when cotransformed with plasmids encoding only the GAL4 DNA-binding domain, a GAL4 DNA-binding domain-CEP1 fusion, or a GAL4 DNA-binding domain-LAM5 fusion (Fig. 1). Further evidence for the specificity of the interaction(s) was obtained by analysis of the effects of specific deletions within the UPF1 portion of the GAL4 DNA-binding domain-UPF1 fusion: Deletions in all but one segment of the UPF1-coding region eliminated Nmd2p-Upf $1 \mathrm{p}$ inter- 


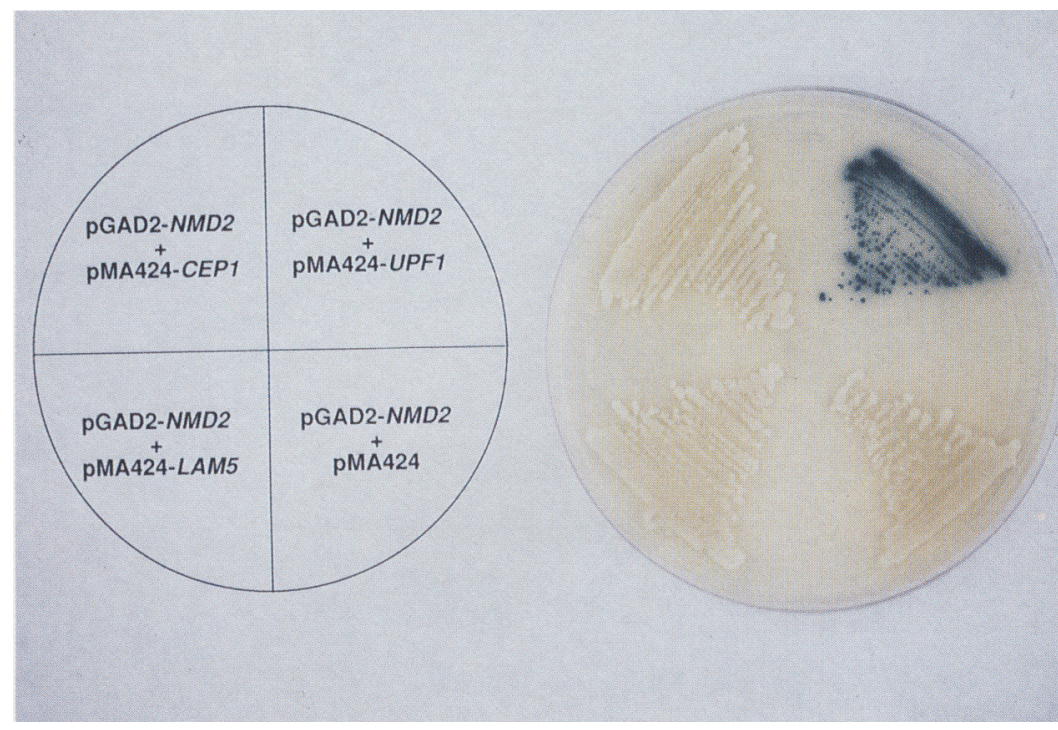

Figure 1. The UPF1 protein interacts specifically with the NMD2 protein. The $S$. cerevisiae tester strain GGY1::171 was cotransformed with the original library isolate pGAD2NMD2 and one of the following plasmids: (1) pMA424-UPF1, a GAL4 DNA-binding domain-UPF1 fusion; (2) pMA424-CEP1, a GAL4 DNA-binding domain-CEP1 fusion; (3) pMA424-LAM5, a GAL4 DNA-binding domain-LAM5 fusion; or (4) pMA424, the GAL4 DNA-binding domain vector. Individual $\mathrm{Leu}^{+}$ $\mathrm{His}^{+}$transformants were selected and streaked on synthetic medium plates lacking histidine and leucine. $\beta$-Galactosidase activity assays were performed by replica-plating of the transformants onto SSX plates containing X-gal. Cells were incubated at $30^{\circ} \mathrm{C}$ for $24-48 \mathrm{hr}$ for development of blue color. action in the two-hybrid assay (F. He, A. Brown, S.W. Peltz, and A. Jacobson, in prep.).

The GAL4 activation domain-NMD2 plasmid recovered in the two-hybrid screen contains only a fragment of the NMD2 gene. To isolate the entire gene, a $1.2-\mathrm{kb}$ ClaI-EcoRI fragment downstream of the GAL4 activation domain in the fusion plasmid was used to screen a yeast YCp50 genomic DNA library (Fig. 2B; Rose et al. 1987). Two independent clones with identical restriction patterns were isolated. By restriction mapping, Southern analysis, and subsequent testing for complementation of an NMD2 chromosomal deletion (Fig. 2C), we localized the NMD2 gene to a $5.2-\mathrm{kb}$ XbaI-SalI DNA fragment (Fig. 2B). To obtain a physical map position for the NMD2 gene, the 1.7-kb XbaI-ClaI fragment was used to probe PrimeClone blots containing characterized fragments of most of the $S$. cerevisiae genome (Olson et al. 1986; Link and Olson 1991). Hybridization was detected to only one fragment (ATCC no. 7155) known to lie on the right arm of chromosome VIII (data not shown). This fragment is located between the put 2 and CUP1 loci at a map position $\sim 260 \mathrm{~kb}$ from the left telomere (Riles et al. 1993). Interestingly, sup111, a recessive omnipotent nonsense suppressor, has been mapped genetically to the vicinity of this position (Ono et al. 1986); we have not, however, tested whether NMD2 and sup111 are allelic.

\section{Primary sequence of the NMD2 gene}

The complete sequence of the NMD2 gene was determined (GenBank accession no. U14974; Fig. 3). The NMD2-coding region is 3267 nucleotides in length, encoding an acidic (predicted $\mathrm{pI}=4.8$ ) protein of 1089 amino acid residues with a predicted molecular mass of $126 \mathrm{kD}$. This interpretation of the NMD2 sequence relies on the prediction of a 113-nucleotide intervening sequence that commences at position +7 and divides the gene into two exons (Fig. 3). Four observations support the existence of this intron. First, the sequence contains all three of the standard consensus sequences expected of an intron [ $5^{\prime}$ splice site (GUAUGU), branchpoint (UACUAACl, and 3 ' splice site (AG)] (Fig. 3). Second, as is true for most introns in yeast (Fink 1987), this intron is located at the $5^{\prime}$ end of the NMD2 gene (six nucleotides downstream from the predicted initiator ATG; Fig. 3). Third, we could detect specific primer extension products by use of two different oligonucleotide primers complementary to mRNA sequences downstream of the predicted 3' splice site, but not by use of a primer complementary to sequences within the intron /data not shown). Finally, using the FLAG or c-MYC epitope tags (Evan et al. 1985; Hopp et al. 1988; Prickett et al. 1989) and epitope-specific monoclonal antibodies, we could only detect the expression of a $126-\mathrm{kD}$ polypeptide when the FLAG or $c-M Y C$ sequences were inserted adjacent to the putative initiator ATG (FLAG-2-NMD2 or c-MYCNMD2 alleles) but not when the FLAG sequence was inserted adjacent to the second ATG (FLAG-1-NMD2 allele; Fig. $4 \mathrm{~B}$ ). The second ATG is located within the putative intron, 37 nucleotides downstream of the predicted intron branchpoint, and is in-frame with the major downstream open reading frame (ORF) but not with the first ATG. It is important to note that both the FLAG-1-NMD2 and FLAG-2-NMD2 alleles are functional in that they both show wild-type ability to complement a chromosomal deletion of NMD2 (Figs. $2 \mathrm{C}$ and 4A). These results indicate that the FLAG-1 sequence inserted downstream of the second ATG has been removed by splicing, indirectly pointing to the existence of the intron in the NMD2 gene.

Analysis of the NMD2 transcript was consistent with the predicted ORF. Northern analysis of total RNA isolated from cells harboring either single or multiple copies of the NMD2 gene identified a transcript of $\sim 3.6 \mathrm{~kb}$ in size (Fig. 5A). By primer extension, multiple transcription initiation sites were mapped to positions $-56,-60$, 
Figure 2. DNA fragments associated with NMD2 function. (A) Restriction map of the nmd2::HIS3 allele. The XbaI-ClaI fragment of the $N M D 2$ gene, including $444 \mathrm{bp}$ of the promoter region and $1286 \mathrm{bp}$ from the coding region, was deleted and replaced with the yeast HIS3 gene. The shaded arrow represents the HIS 3 gene and indicates the direction of transcription. The unshaded arrow represents the NMD2 open reading frame. $(B)$ Restriction map of the NMD2 gene. The NMD2 gene, cloned in YCp50, is located within a $5.2 \mathrm{~kb}$ Xbal-Sall fragment. The NMD2 ORF and direction of transcription are indicated by an open arrow interrupted by a shaded box that indicates the position of the intron. The box labeled probe indicates the DNA fragment used for screening the genomic DNA library. In $A$ and $B$, the solid box represents a segment from the cloning vector YCp50, and the restriction site abbreviations are $(\mathrm{B})$ BamHI; (C) ClaI; (E) EcoRI; (H) HindIII; (P) PstI; (S) SalI; (Xb) XbaI. (C) NMD2 complementation analysis. Lines represent DNA fragments that were subcloned into pRS315. These constructs were transformed into the yeast strain HFY1300, which contains a partial chromosomal deletion of NMD2 (see Fig. 2A) and lacks nonsense-mediated mRNA decay activity (see Fig. 6A-D). Total RNA was isolated from these transformants, and Northern analysis was performed with a radiolabeled probe derived from the CYH2 gene (He et al. 1993). Complementing activity was scored by measuring the relative abundance of the CYH2 pre-mRNA and mRNA in each strain /data not shown). $(+$ and -1 The ability or inability, respectively, to complement the NMD2 chromosomal deletion, i.e., to restore the CYH2 pre-mRNA to the marginally detectable levels characteristic of wild-type cells (He et al. 1993). FLAG-2 and c-MYC epitope-tag sequences were inserted adjacent to the NMD2 initiator ATG codon and FLAG-1 was inserted adjacent to the ATG in the NMD2 intron (see Fig. 3).

-64 , and -67 (Fig. 5B). A putative TATA box, required for most RNA polymerase II transcription (Struhl 1987), lies at positions -219 to -213 in the NMD2 promoter region and another regulatory element, an Abf 1 p-binding consensus sequence (Della Seta et al. 1990), is located within positions -198 to -186 (Fig. 3).

Structural features of the NMD2 protein $(\mathrm{Nmd} 2 \mathrm{p})$ inferred from the sequence analysis include a highly acidic interval $(36.8 \%$ aspartic acid and $25.6 \%$ glutamic acid) from residues 843 to 975 near the carboxyl terminus and a possible bipartite nuclear localization signal at the protein's amino terminus (i.e., within residues 26-29 and 42-46) (Fig. 3; Dingwall and Laskey 1991). Comparison of the Nmd2p sequence with those in the SWISSPROT and PIR protein sequence data bases did not reveal any extensive identity with known protein sequences but did identify three Nmd2p domains with substantial similarity to regions of other proteins: The first, spanning Nmd2p amino acids $1-390$, shows $47 \%$ similarity with translational elongation factor 2 (Eft $1 \mathrm{p}$ and $\mathrm{Eft} 2 \mathrm{p}$ ) from $S$. cerevisiae (Perentesis et al. 1992); the second, from amino acid 400 to 810 in Nmd2p, shares $42.6 \%$ similarity with the $S$. cerevisiae mitochondrial RNase $P$ protein Rpm2p (Dang and Martin 1993); and the third, encompassing the acidic stretch from amino acid 820 to 940 , shows $63.2 \%$ similarity with human and mouse nucle-

Figure 3. DNA sequence and deduced amino acid sequence of NMD2. Cloning of the NMD2 gene and determination of its DNA sequence are described in Materials and methods. The predicted amino acid sequence is indicated in single-letter code and shown below each line of DNA sequence. Position number 1 corresponds to the A of the ATG initiation codon. The NMD2 ORF is interrupted by an intron of 113 nucleotides in which the conserved 5' splice site (GUAUGU), branchpoint (UACUAAC), and 3' splice site (AG) are underlined. Transcription initiation sites at nucleotides $-56,-60,-64$, and -67 (relative to the initiator ATG) were determined by primer extension analysis and are indicated by vertical arrows. The putative TATA box and Abflp-binding consensus sequence, located between positions -219 and -213 and -198 and -186 in the NMD2 promoter region are, respectively, underlined by dashed lines. Double underlined residues fit the consensus for a bipartite NLS (Dingwall and Laskey 1991). The positions where FLAG- or MYC-epitope tag sequences were inserted are indicated by lollipops, and the position where the original GAL4-NMD2 fusion begins is indicated by an arrow with a right angle stem. The GenBank accession number for this sequence is U14974. 
olins (Lapeyre et al. 1987; Bourbon et al. 1988) and 65\% similarity to the mammalian polymerase I transcriptional factors hUBF and mUBF (Jantzen et al. 1990; Hisatake et al. 1991).

\section{NMD2 is not essential for cell viability}

To determine whether the NMD2 gene is essential for cell viability, we performed a gene disruption experi-

-361 CCTGATGACCTTTATCTTAATTATGCACCATCATATAGCGTTTCTATCA TCACTACGOCATATTATGATA:TGTTAOGOGGTTA TATTGAMTATTTCTTAGGGCATGAOGATEATATTA

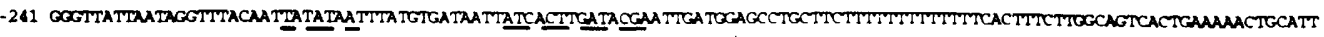
$\downarrow+1$

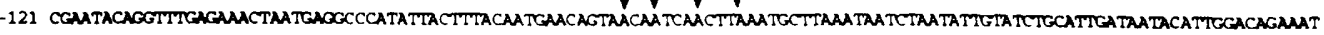

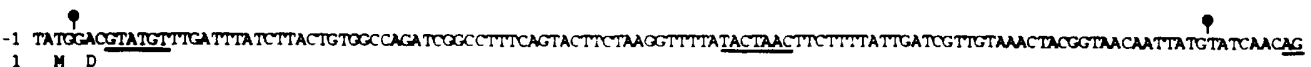

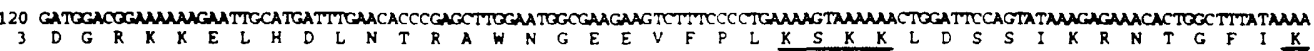

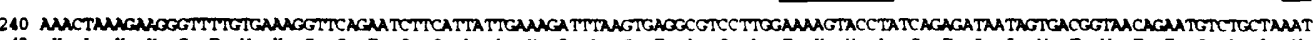

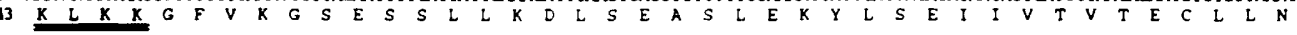
360 GTTTTCMTTMMATCATGACGTMATTGCCGCTGTTCAGATCATMAGTOGACTTCATCAAGGTTCAATGGCCGATTTACTAGTCCGCTTTTIAGGACTITTTTACMACCTTTTCACAAC

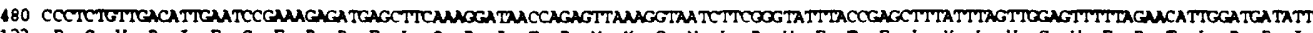

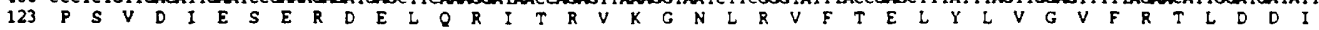

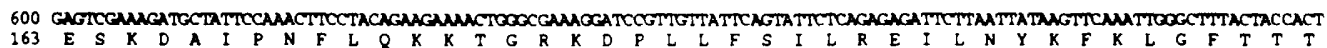

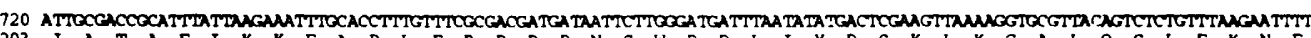
203 I A T A F I K K F A P L F R D D D N S W D D L I Y D S K L K G A L Q

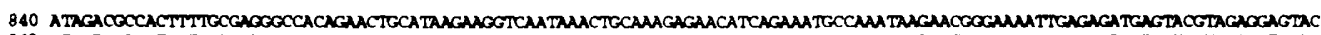
243 I $D$ A T F A R A T E L H K X V N K L Q R E H Q K C C Q I R T G

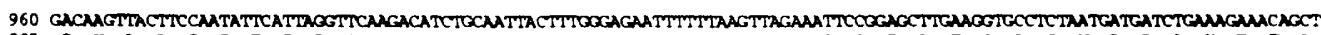

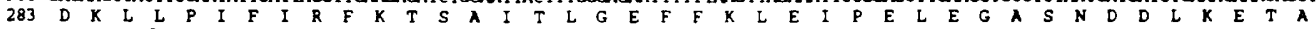

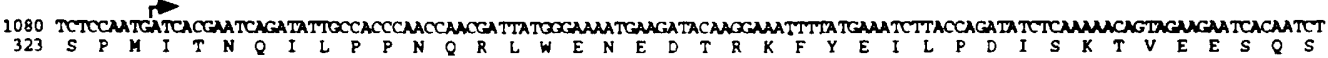

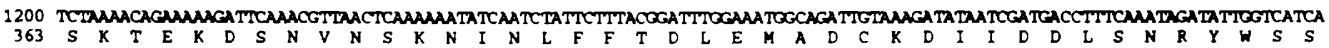

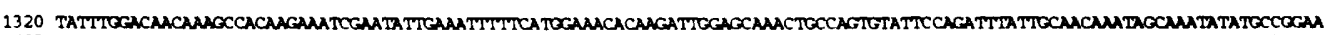

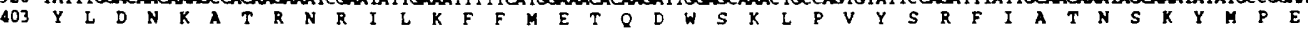

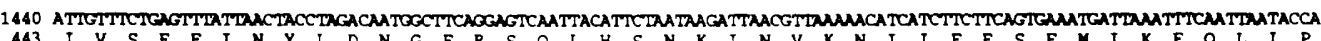

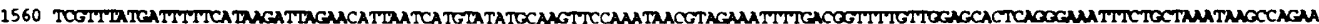
483 S F M I F H K I R T L I

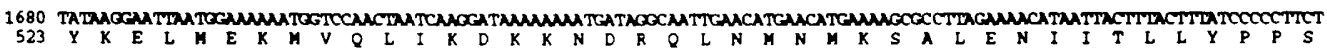

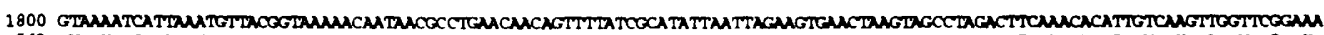
563 V K S S L N V T V K

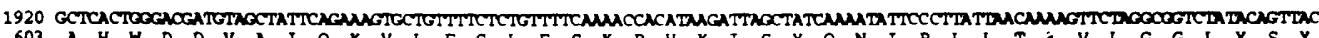

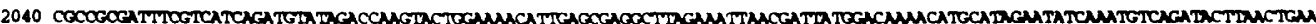
643 R R D

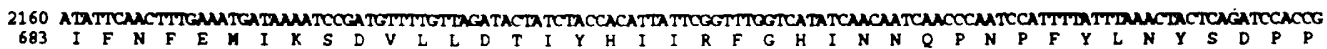

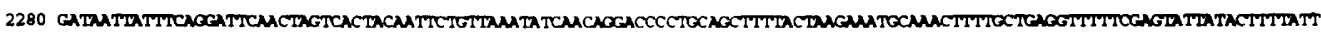

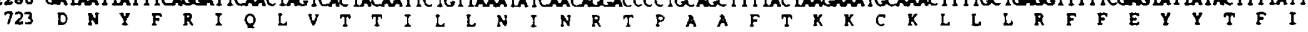

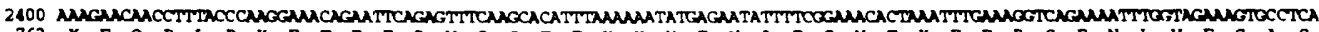

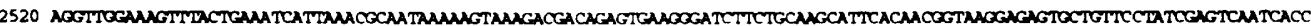
803 R L 2640 GAGATGATGAGGATGAACATGATGAMACCACGATGGTGTCGATTTACTAOGAGAAGATGAAGACGCOGAGATAAGTACACCGAACACAGAGTCAGCGCCAGGAMACATCACOCAAAG

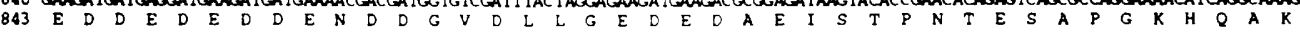

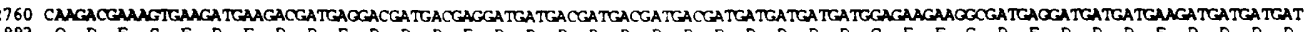
2880 GAOGATGATCATGATGAACAAGAAGAAGACAGCGACTCTGATTTOGAGTA TGGTOGTGATCTTGACGCAGACAGAGATA TTGAAATGAAACGATGTATGMGAGTACGAGAGAAAACTA

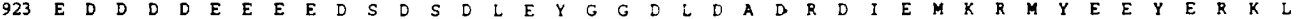
3000 AAOGATGAGGAAGAAAGGAAAGOGGAACAAGAATTOGAAAOGCAATTTCAGAAAATCA TGCAACAATCCATAGACGCAAGCAAAAGCCAAAAGTTGTTGCCAGTAAAATTCCAGTAATT 963 K $D$ D E 3120 TCGA,CCAGTCAGCGTTCAAAAACCTTTATTATTAAAMAAGAGTGAAGAACCTTCTTCAAGCAAGGAGACCTACGAAGAGTTATCCAAGCCAAAGAAGATTGCATTTACGTTCTTGACT 3240 AAAAGCOGTAAGAACACACAATCAAGAATTTTACAATTACCAACOGATGTGAAATTTGTCTCTGATGTCCTTCAACAAGAACAGAAACTAAMAACCGAGCCAMACAAGATTAAAAAGATT 1043 K S G K K T Q S R I L Q L P T D V K F V S D V L E E E E K L K T E R N K I K K I

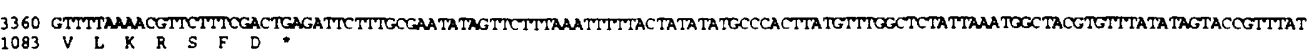

3480 GACGCTGTA TTITTATTTACACTGC TTTC CAOGAGATTAAAGAGCGCAGTGTTAGTCAACTCTCACCACAACAACAGTTATATCGTC TTCTITACCACCGCTGTAGTTITIGCCAGTTAG 3600 CTTAGAAATCTCTTGCGCAAAAACACTOGOGTAATTGGOGTCCTTGCTTAAACTGACAACA TTGTCCACAAACTTCTOGCATAATAGCTGTAACTCATCGTTTGTTCTCGCAGCGTTATC

Figure 3. (See facing page for legend.) 
Figure 4. Expression of epitope-tagged NMD2 alleles. Strains expressing FLAG- or MYC-epitopetagged NMD2 alleles were constructed as described in Materials and methods. $(A)$ The epitope-tagged $N M D 2$ alleles are fully functional. Total RNA was isolated from the following strains: (Lane 1) HFY2302 harboring pRS315NMD2(X-S); (lane 2) HFY2303 harboring pRS315F1-NMD2(X-S); (lane 3) HFY2304 harboring pRS315-F2-NMD2(X-S); (lane 4) HFY2305 harboring pRS315-MYC-NMD2(X-S); (lane 5) HFY2301 containing pRS315 only. RNA was frac-

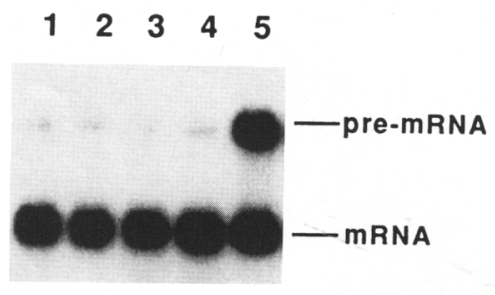

(A)

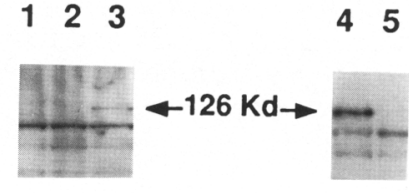

(B)

tionated by gel electrophoresis and analyzed by Northern blotting with a probe from the CYH2 gene. $(B)$ Immunoblot analysis. Whole-cell extracts were prepared from the yeast strains described above. Equivalent amounts of extract from each strain were fractionated by SDS-PAGE and transferred to Immobilon-P filters. Immunoblots were probed either with anti-FLAG monoclonal antibody (M5) (lanes 1-3) or anti-MYC monoclonal antibody (9E10) (lanes 4-5) as described in Materials and methods. The Nmd2pspecific band is indicated by an arrow.

ment in which the 444-bp 5'-noncoding segment of the gene and the first $1286 \mathrm{bp}$ of $\mathrm{Nmd} 2 \mathrm{p}$-coding sequence were deleted and replaced by the HIS3 gene (Fig. 2A). The nmd2::HIS 3 construct was targeted to the NMD2 chromosomal locus in the diploid W303 (Thomas and Rothstein 1989) by homologous recombination, and correct integration was verified by Southern analysis of chromosomal DNA (Fig. 6A). Consistent with the replacement of $N M D 2$ by $n m d 2:: H I S 3$, DNA from transformed strains contains EcoRI fragments of 7.0 and 1.2 $\mathrm{kb}$ that are complementary to an NMD2 probe (Fig. 6A, lane $\mathrm{P} 2$ ), whereas the nontransformed strain contains only the $7.0-\mathrm{kb}$ fragment (Fig. 6A, lane P1). (The latter fragment most likely contains the only NMD2 sequences in the genome, that is, the NMD2 gene is unique, because hybridization of another NMD2 probe to PrimeClone blots also identified only a single DNA fragment (see above)]. After sporulation and tetrad dissection, the transformed diploid yielded four viable spores from each tetrad with two being prototrophic and two auxotrophic for histidine (data not shown). Haploid strains containing the nmd2::HIS3 disruption (Fig. 6A, lanes $1 \mathrm{C}, \mathrm{D}$ ) were compared with isogenic $N M D 2$ strains (Fig. 6A, lanes 1A,B) for their ability to grow on different carbon sources (glucose, galactose, and glycerol) at temperatures ranging from $18^{\circ} \mathrm{C}$ to $37^{\circ} \mathrm{C}$ and no differences in growth rates were detected between mutant and wildtype strains (data not shown). These data indicate that $N M D 2$ is nonessential for cell viability.

\section{NMD2 disruption selectively stabilizes nonsense- containing $m R N A s$}

Previously, we have shown that mutation or deletion of the UPF1 gene leads to a selective stabilization of a class of mRNAs in which translation has terminated prematurely (Leeds et al. 1991; He et al. 1993; Peltz et al. 1993). This class includes mRNAs with early nonsense or frameshift mutations as well as intron-containing premRNAs that have entered the cytoplasm (He et al. 1993). The latter group includes inefficiently spliced pre-mRNAs (e.g., the transcripts of the CYH2 and RP51B genes) and pre-mRNAs whose splicing is regulated (e.g., the transcript of the MER2 gene). We expected that mutation of a gene encoding a bona fide Upflp-interacting protein would most likely lead to the same nonsense-mediated mRNA decay phenotype as mutation of the UPF1 gene. Because disruption of the NMD2 gene was not lethal, it was possible to compare the activity of the nonsensemediated mRNA decay pathway in both NMD2 and nmd2::HIS3 strains.

Yeast centromere plasmids carrying six different PGK1 nonsense alleles were constructed previously (Peltz et al. 1993). These plasmids were transformed into NMD2 and nmd2::HIS3 strains, and the abundance of PGK1 nonsense-containing mRNAs was assessed by northern blotting. As was observed previously (Peltz et al. 1993), nonsense mutations in the first two-thirds of the PGK1-coding region reduced the abundance of the corresponding mRNAs 5- to 20-fold (Peltz et al. 1993). The abundance of PGK1 mRNAs with nonsense mutations beyond this point is unaffected. Disruption of the NMD2 gene restored wild-type levels to all four of the PGK1 transcripts normally subject to nonsense-mediated mRNA decay (Fig. 6C). As a control, the abundance of the wild-type PGK1 and ACT1 mRNAs and the halflife of the MAT 1 mRNA in the same cells was measured and shown to be unaffected by the nmd2::HIS3 disruption (data not shown). Northern analysis was also used to measure the relative abundance of the CYH2, $R P 51 B$, and MER2 pre-mRNAs in $N M D 2$ (Fig. 6B, lanes $1 \mathrm{~A}, \mathrm{~B}$ ) and $n m d 2::$ HIS3 strains (Fig. 6B, lanes $1 \mathrm{C}, \mathrm{D}$ ). We found that the abundance of the inefficiently spliced CYH2 and RP51B pre-mRNAs, and the MER2 premRNA (whose splicing is regulated by MER1; Engebracht et al. 1991) was markedly increased in strains carrying the $n m d 2:: H I S 3$ disruption. That this increase in RNA abundance was attributable to a reduction of mRNA decay rates is shown in Figure 6D. Disruption of the NMD2 gene reduces the decay rate of the CYH2 premRNA approximately fourfold, that is, from a half-life of $1.5 \mathrm{~min}$ to a half-life of $6.0 \mathrm{~min}$ without a concomitant effect on the half-life of the CYH2 mRNA (Fig. 6D). These results are identical to those obtained in UPF1 


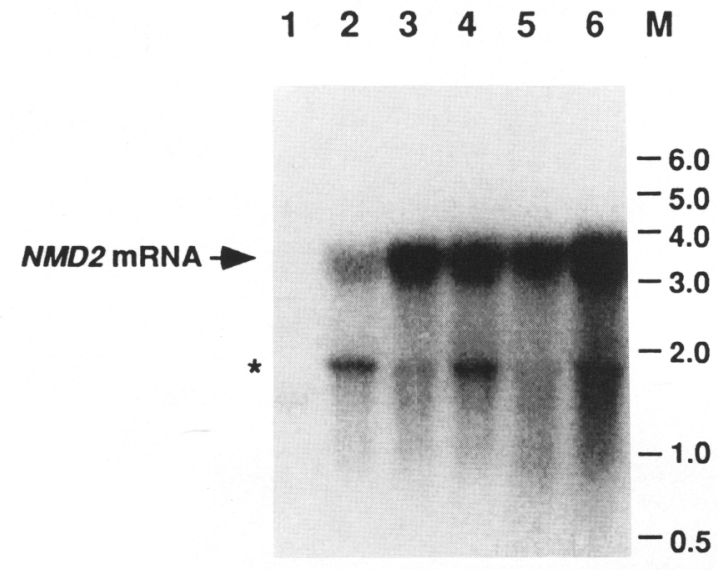

(A)
12 G A T C
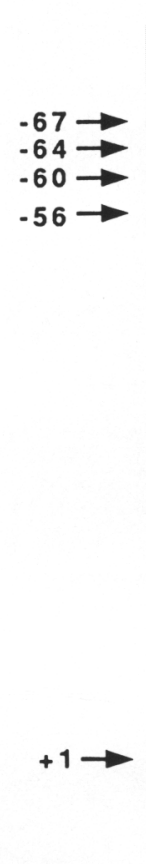

(B)
Figure 5. Analysis of the NMD2 transcript. (A) Northern analysis of total RNA from yeast strains containing multiple copies of the NMD2 gene. (Lane 1) HFY1307 harboring YEplac112; (lanes 2,3) HFY1308 harboring YEplac112-NMD2(X-S); (lanes 4,5) HFY1309 harboring YEplac 1 12-F2-NMD2(X-S); (lane 6) HFY1310 harboring YEplac112-HA$N M D 2(\mathrm{X}-\mathrm{S})$. A radiolabeled probe derived from the 1.7-kb Xbal-ClaI fragment of NMD2 was hybridized to the filter. The positions to which molecular weight markers migrated are indicated as is the position of the NMD2 mRNA (arrow). The lower molecular weight band detected in several lanes (see asterisk) may be a product of alternative transcription initiation or termination. A $3.6-\mathrm{kb}$ NMD2 mRNA of significantly lower abundance than the mRNAs depicted here is also detected by Northern blotting of RNA from cells harboring a single copy of the NMD2 gene (data not shown). (B) Primer extension analysis of the NMD2 transcript. Total RNAs were isolated from strains W303 (lane 1) and HFY1300 (lane 2). HFY 1300 contains a partial chromosomal deletion of NMD2 (see Fig. 2A). A radiolabeled primer (NMD2-5) was annealed to total RNA and extended by AMV reverse transcriptase. NMD2 DNA sequence reactions with the same primer (run on lanes $G, A, T, C$ ) were used to determine the positions of the primer extension products. The transcription initiation sites (relative to the initiator ATG) are indicated. knockout strains (He et al. 1993) and indicate that NMD2 is a novel component of the nonsense-mediated mRNA decay pathway and that Nmd2p is most likely a bona fide Upflp-interacting protein.

\section{The acidic carboxyl terminus of $\mathrm{Nmd} 2 \mathrm{p}$ interacts with Upf1p}

DNA sequence analysis indicated that the original NMD2 isolate, the GAL4 activation domain-NMD2 fusion plasmid, encoded 764 amino acids from the carboxy-terminal segment of $\mathrm{Nmd} 2 \mathrm{p}$ (Figs. 3 and 7). To identify the region of $\mathrm{Nmd} 2 \mathrm{p}$ that interacts with Upf $1 \mathrm{p}$, we generated $5^{\prime}$ and $3^{\prime}$ deletions of the original NMD2 fragment (see Materials and methods), fused them inframe to the GAL4 activation domain, and assayed for interaction with Upflp by use of the two-hybrid system. Fusions encoding either 237 or 477 amino acids from the amino-terminal half of the original fragment demonstrated no detectable $\beta$-galactosidase activity in the presence of the GAL4 DNA-binding domain-Upflp fusion (Fig. 7, $\Delta 3$ and $\Delta 4$, respectively). However, fusions encoding either 526 or 286 amino acids from the carboxyl terminus of the original fragment demonstrated detectable $\beta$-galactosidase activity (Fig. $7, \Delta 1$ and $\Delta 2$, respectively). These results indicate that the acidic carboxy-terminal domain of Nmd2p interacts with Upflp.
A double mutant, containing disruptions of both the UPF1 and NMD2 genes is phenotypically identical to either upf1 or nmd2 single mutants

The identification of $\mathrm{Nmd} 2 \mathrm{p}$ as a Upf1p-interacting protein in a two-hybrid screen and the observation that disruption of the NMD2 gene yielded a nonsense-mediated mRNA decay phenotype identical to that obtained in strains harboring upf1 mutations strongly suggests that Upflp and Nmd2p interact with each other in vivo and that they perform different functions in the same decay pathway. This conclusion was strengthened by analysis of double mutants in which both the UPF1 and NMD2 gene products are functionally absent. A upf1::URA3 allele in which $1033 \mathrm{bp}$ of the UPF1-coding region from nucleotides 1095-2128 was deleted and replaced by the URA3 gene was constructed (Leeds et al. 1992). The upf1::URA3 and nmd2::HIS3 double mutant was constructed by transformation of the upf1::URA3 allele into the haploid strain HFY1300, which harbored an nmd2::HIS3 allele. Correct integration of upf1::URA3 was verified by Southern analysis of chromosomal DNA (data not shown). The haploid strain containing both the upf1::URA3 and nmd2::HIS3 alleles was viable and did not demonstrate any growth defect in comparison to the haploid strains containing only single disruptions. Total RNA was isolated from strains carrying UPF1/NMD2, upf1::URA3/NMD2, UPF1/nmd2::HIS3, 
(A)
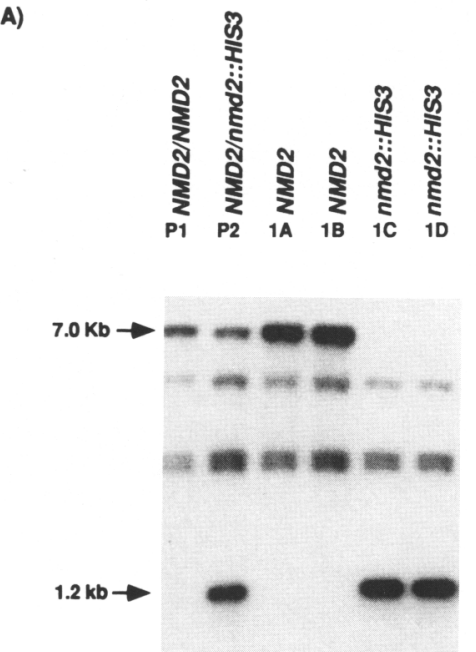

(B)
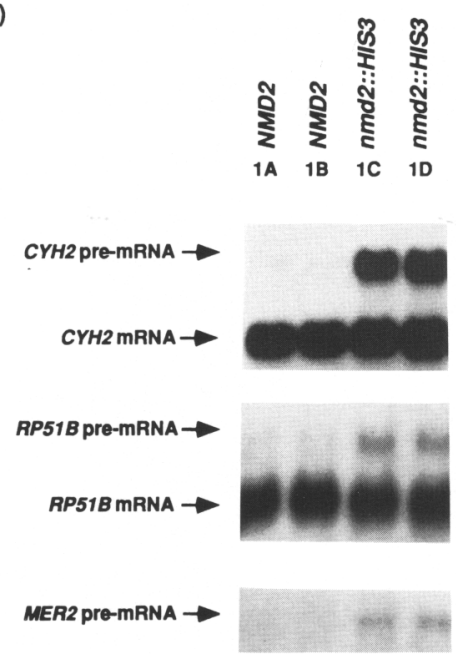

(C)
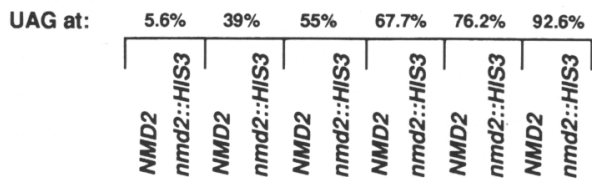

(D)

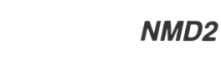

NMD2
nmd2::HIS3

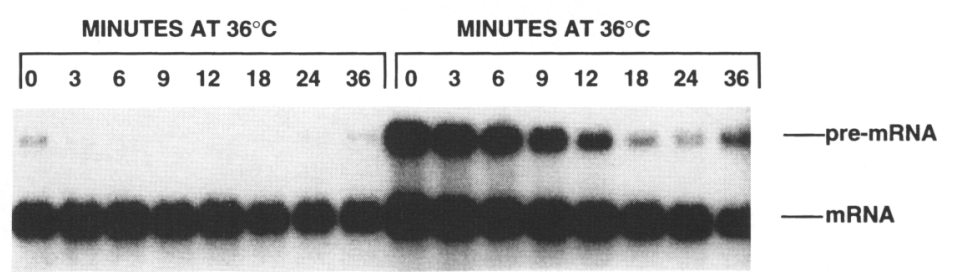
of the NMD2 gene. $(A)$ Southern analysis of the NMD2 gene disruption. A SacI-Sall fragment carrying the nmd2::HIS3 allele was isolated from plasmid Bs-nmd2::HIS3 and used to transform the yeast diploid strain W303. His $^{+}$transformants were sporulated, and tetrads were individually dissected. Four viable spores were obtained from each tetrad analyzed. Genomic DNAs from parental diploid and progeny haploid strains were isolated, digested with EcoRI, and analyzed by Southern blotting with a radiolabeled probe derived from the 1.2 -kb ClaI-EcoRI fragment. (Lane P1) DNA isolated from the homozygous NMD2/NMD2 diploid strain W303; (lane P2) DNA isolated from a diploid His ${ }^{+}$ transformant of W303 (HFY1000); (lanes 1A-1D) DNA isolated from the progeny of four viable spores dissected from the same tetrad (HFY1100, HFY1200, HFY1300, and HFY1400). The 7.0- and 1.2-kb fragments represent the wild-type and disrupted alleles of NMD2, respectively. Other bands are not specific to NMD2. $(B)$ Disruption of the NMD2 gene increases the relative abundance of introncontaining pre-mRNAs. Total RNA was isolated from each of the four progeny haploid strains derived from the same tetrad described in $A$. Northern blots were hybridized with DNA probes described previously (He et al. 1993) that were specific for the $C Y H 2, R B 51 B$, or MER2 transcript. The corresponding mRNAs and pre-mRNAs are indicated. $(C)$ Disruption of the NMD2 gene stabilizes $P G K 1$ mRNAs containing early nonsense mutations. The construction of isogenic NMD2 and nmd2::HIS3 haploid yeast strains haboring different nonsense-containing PGK1 alleles (HFY1201 to HFY1206 and HFY1301 to HFY1306) is described in Materials and methods. Total RNA was isolated from these strains and analyzed by Northern blotting with a radiolabeled oligonucleotide probe complementary to the tag sequence located in the $3^{\prime}$-untranslated region of $P G K 1$ nonsense-containing mRNAs (Peltz et al. 1993). The location of the nonsense mutation in each $P G K 1$ transcript is presented as a percentage of the PGK1 protein-coding region that is translated before the mutation is encountered (Peltz et al. 1993). (D) Disruption of the NMD2 gene reduces the decay rate of the CYH2 pre-mRNA. Decay rates of $C Y H 2$ pre-mRNA and mRNA were determined by Northern analysis of RNAs isolated at different time points after transcription was inhibited by shifting of cultures of isogenic NMD2 (HFY2206) and nmd2 (HFY2106) strains to $36^{\circ} \mathrm{C}$. Samples were taken for $36 \mathrm{~min}$, and the blot was hydridized with a radiolableled CYH2 DNA probe.

and upf $1:: U R A 3 / n m d 2:: H I S 3$ alleles, respectively. Northern analysis with a fragment of the $C Y H 2$ gene as a probe demonstrated that the abundance of the $C Y H 2$ premRNA was essentially identical in strains carrying either the single upf1::URA3 or nmd2::HIS3 disruptions or the double disruption (Fig. 8A). These results indicate that Upf1p and Nmd2p must function in closely related steps of the nonsense-mediated mRNA decay pathway.

\section{Overexpression of truncated Nmd2p in the cytoplasm results in a dominant-negative nonsense-mediated mRNA decay phenotype}

Nonsense-mediated mRNA decay in yeast appears to be cytoplasmic and is linked to translation (see introduc- tory section). Moreover, recent experiments employing immunofluorescence microscopy and immunoelectron microscopy indicate that Upflp is present predominantly in the cytoplasm, although a subfraction is detectable in the nucleus (A.H. Brown, F. He., C. Powers, R. Singer, and A. Jacobson, unpubl.). To identify the functional sites for Upflp in this decay pathway, we expressed a truncated form of Nmd2p both in the nucleus and the cytoplasm. The original GAL4 activation domain-NMD2 fusion plasmid encodes 764 amino acids from the carboxy-terminal segment of Nmd2p (Fig. 3). Transcription of this GAL4-activation domain-NMD2 fusion was driven by a cryptic promoter in the $A D H 1$ terminator present in the vector, and the fusion protein was targeted to the nucleus by the SV40 $\mathrm{T}$ antigen nu- 


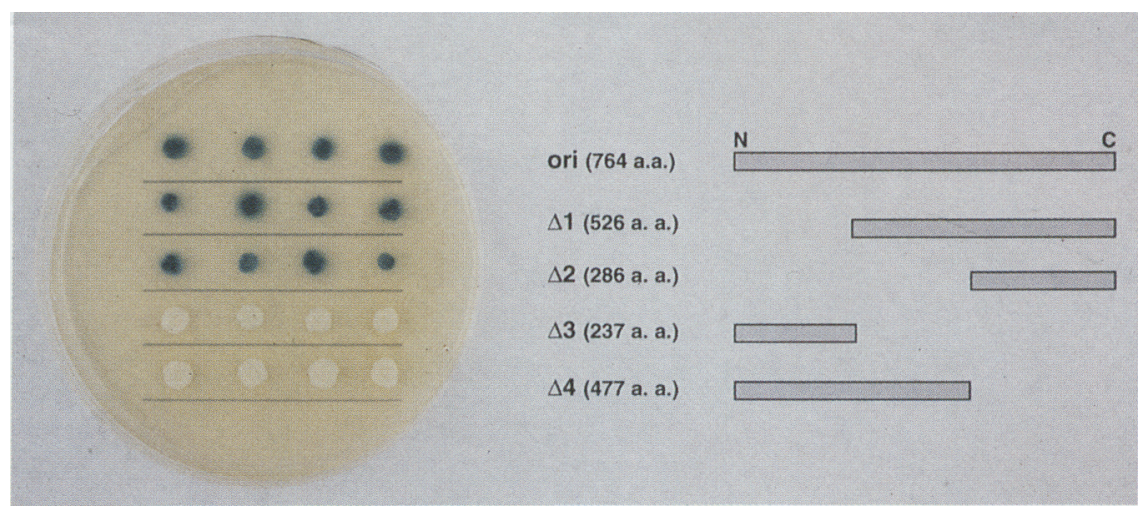

Figure 7. The acidic carboxyl terminus of Nmd2p interacts with Upflp. Deletions (5' and $\left.3^{\prime}\right)$ of the original NMD2 fragment were generated by PCR and fused in-frame to the GAL4 activation domain in pGADIF, resulting in pGADIF-NMD2$\Delta 1,-\Delta 2,-\Delta 3$, and $-\Delta 4$ as described in Materials and methods. The yeast tester strain GGY1::171 was cotransformed with pMA424-UPF1 and pGAD1F-NMD2- $\Delta 1$, $-\Delta 2,-\Delta 3$, and $-\Delta 4$, respectively. $\beta$-Galactosidase activity was assayed as described in the legend to Fig. 1. Fusions encoding either 526 amino acids (pGAD1F-NMD2$\Delta 1$ ) or 286 amino acids (pGAD1F-NMD2$\Delta 2)$ from the carboxyl terminus of the original fragment demonstrated detectable $\beta$-galactosidase activity. Fusions encoding either 237 amino acids (pGAD1F-NMD2- $\Delta 3$ ) or 477 amino acids (pGADIF-NMD2- 44 ) from the amino-terminal half of the original fragment demonstrated no detectable $\beta$-galactosidase activity in the presence of the GAL4 DNA-binding domain-Upflp fusion.

clear localization signal (Chien et al. 1991). The 6.0-kb HindIII fragment encoding this fusion protein was also subcloned into pGAD2F so that transcription of the fusion protein was driven by the more potent $A D H 1$ promoter. Because the SV40 T antigen nuclear localization signal (NLS) of the fusion protein is in a 36-bp EcoRI fragment (Benton et al. 1990), we also generated deletions of the NLS in the respective constructs. Plasmids expressing the different fusion proteins were transformed into the haploid strain HFY1200, which is wildtype for both UPF1 and NMD2. Control experiments, carried out by use of the two-hybrid assay, showed that when NMD2 plasmids lacking the $\mathrm{T}$ antigen NLS were cotransformed with the original plasmid encoding the GAL4 DNA-binding domain-UPF1 fusion, no $\beta$-galactosidase activity was detectable, that is, nuclear localization had been eliminated (Fig. 8C). Total RNA was isolated from transformants, and Northern analysis was carried out with a fragment of the $C Y H 2$ gene as a probe (Fig. 8B). Overexpression of truncated NMD2 fusion protein localized to the nucleus had no effect on the accumulation of the CYH2 pre-mRNA (Fig. 8B, lanes 2,3). Expression of the cytoplasmically localized fusion protein caused an accumulation of $\mathrm{CYH} 2$ pre-mRNA in a dosage-dependent manner, that is, expression of the fusion protein from the stronger promoter led to a greater accumulation of the $C Y H 2$ pre-mRNA than expression from the weaker promoter (Fig. 8B, lanes 5,6). This result demonstrates that at least one function of Upf $1 p$ is cytoplasmic. Moreover, the success of this approach in creating a dominant-negative phenotype establishes overexpression as a means to evaluating whether genes identified in two-hybrid screens are bona fide components of the pathway under investigation.

\section{Discussion}

The NMD2 gene encodes a new factor in the nonsensemediated mRNA decay pathway

Nonsense-mediated mRNA decay is the rapid turnover of an otherwise stable mRNA that ensues when a ribo- some encounters a premature translational termination codon (for reviews, see Peltz and Jacobson 1993; Peltz et al. 1994). In S. cerevisiae, this decay pathway is dependent on the UPF1 and UPF3 gene products (Leeds et al. 1991, 1992; He et al. 1993; Peltz et al. 1993). To identify other integral components of this pathway, we have utilized a two-hybrid screen, seeking those cellular factors that potentially interact with Upflp. Here we show that at least one gene identified in this screen, $N M D 2$, encodes a novel factor specifically required for nonsensemediated mRNA decay. This conclusion follows from the observation that deletion of $N M D 2$ restores wildtype levels and decay rates to nonsense-containing PGK1 mRNAs and to the intron-containing $C Y H 2, M E R 2$, and $R P 51 B$ pre-mRNAs but has no effect on the levels or decay rates of inherently unstable mRNAs. These effects are analogous to those observed in upf $1 \Delta$ strains (He et al. 1993; Peltz et al. 1993). Like the UPF1 and UPF3 gene products (Leeds et al. 1991, 1992), that encoded by NMD2 is not essential for viability and does not appear to discriminate among the different nonsense codons (e.g., the terminator in the RP51B pre-mRNA is UGA and that in the CYH2 and MER2 pre-mRNAs is UAG; He et al. 1993).

Mutants in the UPF1 and UPF3 genes were originally identified on the basis of their ability to act as allosuppressors of the his $4-38$ frameshift mutation. In the same selection that identified those mutants, Culbertson et al. (1980) reported the characterization of two additional allosuppressors, upf2-1 and UPF4-2. upf2 mutants have also been shown to selectively stabilize nonsense-containing mRNAs without concomitant effects on the decay rates of most other mRNAs (S.W. Peltz, P. Leeds, and A. Jacobson, unpubl.). Cui et al. (this issue) describe the cloning and sequencing of UPF2. A comparison of the the NMD2 and UPF2 sequences indicates that they are the same gene. Collectively, the studies of UPF1, $N M D 2 / U P F 2$, and UPF3 indicate that a potent mode of nonsense suppression in yeast involves the restoration of wild-type mRNA levels from which even a modest amount of read-through translation is sufficient to provide minimum levels of a specific protein. 
A
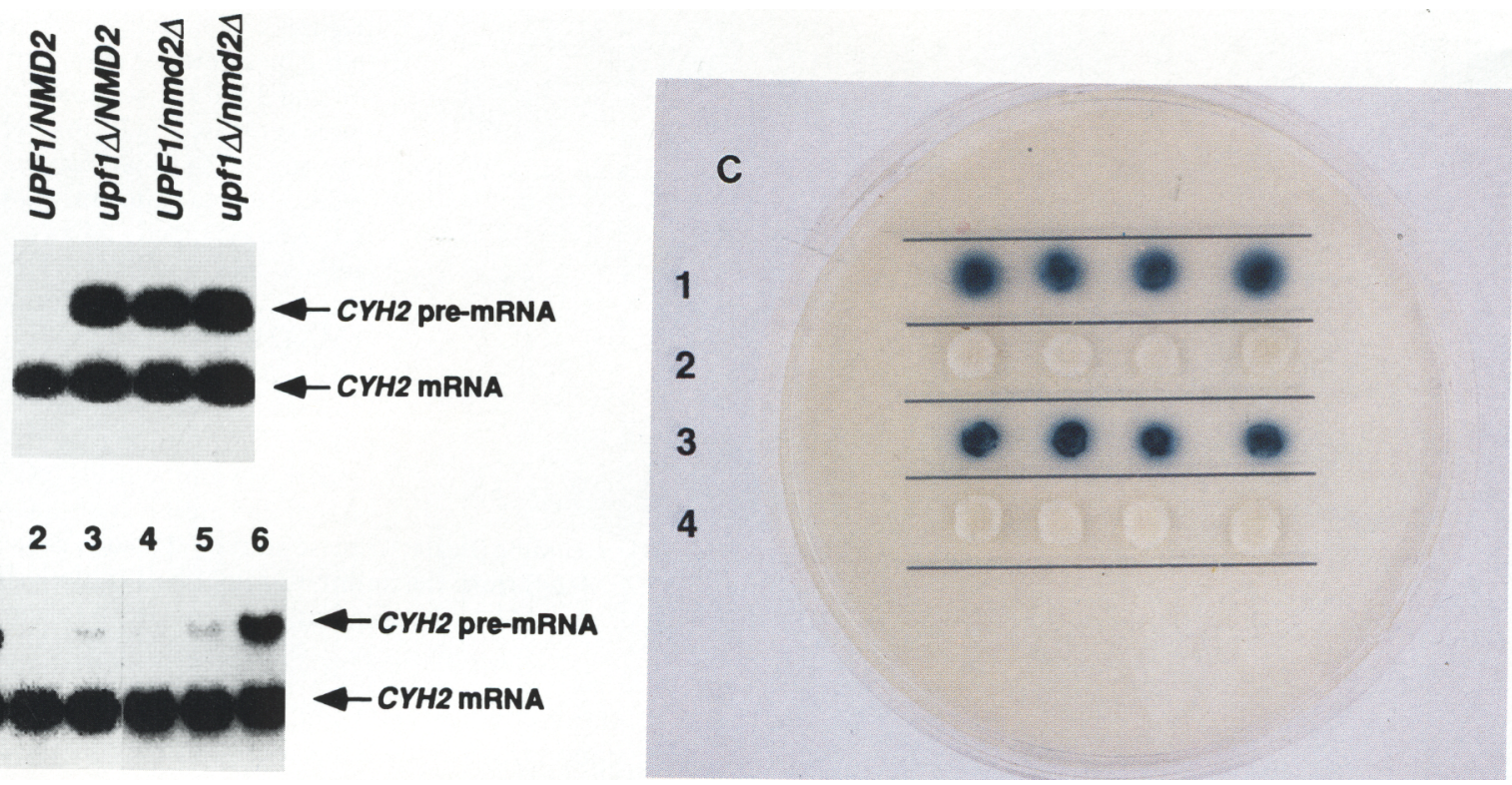

Figure 8. Phenotypes associated with disruption of both the NMD2 and UPF1 genes or overexpression of Nmd2p fragments. $(A) \mathrm{A}$ double mutant containing both upf1::URA3 and nmd2::HIS3 disruptions is phenotypically identical to either upf1 or nmd2 single mutants. Total RNAs were isolated from each of the following strains: HFY3002 (UPF1/NMD2); HFY3005 (upf1 $/$ NMD2); HFY3008 $(U P F 1 / n m d 2 \Delta)$ and HFY3001 (upf $\Delta 1 / n m d 2 \Delta)$. RNAs were analyzed by Northern blotting with a radiolabeled $C Y H 2$ fragment as probe. $(B)$ Overexpression of truncated $\mathrm{Nmd} 2 \mathrm{p}$ in the cytoplasm results in a dominant-negative nonsense-mediated mRNA decay phenotype. The yeast strain HFY1200, which is wild-type for both UPF1 and NMD2, was transformed with pGAD2F-NMD2-ADH $N M D 2-A D H_{\mathrm{p}}, \mathrm{pGAD} 2 \mathrm{~F}$, pGAD2F-NMD2-ADH $H_{\mathrm{t}}-\Delta \mathrm{NLS}$, and pGAD2F-NMD2-ADH $H_{\mathrm{p}}-\Delta \mathrm{NLS}$, respectively (see Plasmids and Materials and methods|. Total RNA was isolated from these transformants and analyzed by Northern blotting with a CYH2 DNA fragment as probe. Lane 1 contained RNA isolated from HFY 1300 (control); RNA in other lanes was from transformants of HFY 1200 harboring the following plasmids: (lane 2) pGAD2F-NMD2-ADH (lane 3) pGAD2F-NMD2-ADH ; (lane 4) pGAD2F; (lane 5) pGAD2F-NMD2$A D H_{\mathrm{t}}-\Delta \mathrm{NLS}$; (lane 6) pGAD2F-NMD2-ADH $H_{\mathrm{p}}-\Delta \mathrm{NLS}$. (C) Deletion of the SV40 NLS from the GAL4 activation domain-NMD2 fusion abolishes Upflp-Nmd2p interactions in the two-hybrid assay. The yeast strain GGY1::171 was cotransformed with pMA424-UPF1 and one of the following plasmids: (Row 1) pGAD2F-NMD2-ADH $H_{\mathrm{t}}$ (row 2) pGAD2F-NMD2-ADH $-\Delta N L$ S $_{\text {; }}$ (row 3) pGAD2F-NMD2$A D H_{\mathrm{p}}$ (row 4) pGAD2F-NMD2-ADH $H_{\mathrm{p}}-\Delta \mathrm{NLS}$. $\beta$-Galactosidase activity was assayed as described in the legend to Fig. 1.

NMD2 encodes a 126-kD polypeptide with limited but provocative homologies to previously characterized proteins. These include a homology within the amino-terminal third of the protein to translational elongation factor 2 (Eft1p and Eft2p), a homology within the middle third of the molecule to the yeast RNase P protein, Rpm2p, and a homology within the acidic carboxyl terminus of Nmd2p to mammalian nucleolins and upstream binding factor (UBF) transcription factors. Although it is premature to ascribe any functions to these $\mathrm{Nmd} 2 \mathrm{p}$ domains, we speculate that the region encompassing the elongation factor 2 homology may interact with components of the translational apparatus and that the region homologous to Rpm2p may, in a manner analogous to the function of Rpm2p itself, bind directly to RNA, perhaps maintaining mRNA substrates in conformations suitable for degradation. The acidic carboxyl terminus of Nmd2p is, as discussed below, required for interaction with Upflp.

\section{Upf1p and Nmd2p are likely to be interacting proteins}

Two-hybrid screens have been used previously to identify numerous pairs of potentially interacting proteins in several different biochemical pathways (for review, see Fields 1993; Fields and Sternglanz 1994). To maximize the possibility that genes identified in such screens actually encode bona fide interactors, several genetic criteria that ensure the specificity of the putative interaction are applied. In particular, it has been important to demonstrate that the library plasmids isolated in such screens score positively for interaction only when paired with a plasmid encoding the fusion protein of interest and not any other proteins (Bartel et al. 1993). As shown in Figure 1, NMD2 fulfills such criteria in that it shows a positive response ( $\beta$-galactosidase expression) only with a GAL4-UPF1 fusion, but not with GAL4-CEP1 or GAL4-LAM5 fusions or with the GAL4 DNA-binding domain alone. Subsequent tests for specificity rely on demonstration of one or more of the following: (1) that specific mutations in the gene used as bait inactivate the putative interaction; (2) that mutation of the gene identified in the screen yields a phenotype consistent with the pathway under study; or (3) direct physical interaction. As shown in Figure 6, B-D, NMD2 must be a component of the nonsense-mediated decay pathway because disruption of the gene inactivates the pathway. Further evidence that Upflp and $N m d 2 p$ are interacting proteins 
is provided by the observation that cells containing disruptions of both the NMD2 and UPF1 genes are phenotypically identical to cells containing either single mutation (Fig. 8A) and the demonstration that overexpression of an Nmd2p fragment targeted to the cytoplasm has a dominant-negative effect on nonsense-mediated mRNA decay (Fig. 8B). It remains to be established whether Nmd2p and Upflp interact directly or are bridged by yet another factor. We consider it unlikely that a bridging factor exists because such a factor would have to be localized to nuclei and present at concentrations high enough to compensate for the overexpression of both genes in the screen and because preliminary experiments indicate that Upflp and Nmd2p can be coimmunoprecipitated (F. He and A. Jacobson, unpubl.).

Proof that a previously uncharacterized gene identified in a two-hybrid screen is a bona fide component of the pathway under study is often difficult to obtain and generally involves cloning and sequencing of the entire gene as well as additional manipulations, for example, mutation of the gene. These steps are time consuming and, at times, are futile because direct evidence implicating the gene's involvement in the pathway is not always obtained. The association of a dominant-negative phenotype with the overexpression of an Nmd2p fragment suggests an additional and more rapid approach to assessing the importance of genes identified in these screens. We consider it likely that overexpression of other gene fusions identified in two-hybrid screens will have comparable dominant-negative effects and that such effects will be particularly informative about the role of the gene product in question. A similar rationale was used by Ramer and co-workers (1992) in their demonstration that a conditional expression library could be used to identify genes whose products were toxic when expressed at high levels.

\section{Degradation of nonsense-containing mRNAs in yeast must occur in the cytoplasm}

In mammalian cells several recent reports suggest that nonsense-containing mRNAs are associated with the nuclear fraction when they are degraded (Urlaub et al. 1989; Baserga and Benz 1992; Naeger et al. 1992; Cheng and Maquat 1993; Belgrader and Maquat 1994; Cheng et al. 1994). In Xenopus and yeast, however, the available data suggest that nonsense-mediated mRNA decay occurs in the cytoplasm. In Xenopus, nonsense-containing mRNAs are rapidly and specifically degraded after microinjection into oocytes and embryos (Whitfield et al. 1994) and, in yeast, nonsense-containing mRNAs are (1) found on polysomes in which the extent of ribosome loading varies as a function of nonsense codon position (Leeds et al. 1991; He et al. 1993), (2) dependent on an apparent translational reinitiation site for rapid decay (Peltz et al. 1993, 1994; E. Welch and A. Jacobson, in prep.l, (3) stabilized in strains containing a nonsense suppressor tRNA (Losson and Lacroute 1979), (4) stabilized and fully loaded onto polysomes in cells treated with cyclohexi- mide (Peltz et al. 1993, 1994; S. Zhang, E.M. Welch, K. Hagan, A. Brown, A. Jacobson, and S.W. Peltz, in prep.), and (5) rapidly degraded in cycloheximide-treated cells immediately after removal of the drug (S. Zhang, E.M. Welch, K. Hagan, A. Brown, A. Jacobson, and S.W. Peltz, in prep.). These observations are underscored by the results shown in Figure 8B, which demonstrate that overexpression of a segment of Nmd2p encoding the Upf1pinteracting domain inhibits nonsense-mediated mRNA decay when that polypeptide is targeted to the cytoplasm but not when it is targeted to the nucleus. We interpret this result to indicate that the Nmd2p fragment is a competitive inhibitor of the activity of a cytoplasmic factor required for mRNA decay, possibly Upf lp. This interpretation does not exclude the possibility that important components in the pathway are added to the mRNP during assembly in the nucleus.

mRNA surveillance and the possible functions of Upf1p and Nmd2p

The existence of trans-acting factors that promote rapid decay of nonsense-containing mRNAs raised the question of whether such mRNAs are the sole substrates of these factors, that is, whether the cell has an apparatus to specifically degrade nonsense-containing mRNAs. As discussed above, we have shown recently that the nonsense-mediated mRNA decay pathway is involved in controlling the abundance of pre-mRNAs that enter the cytoplasm (He et al. 1993), an observation consistent with the general absence of contiguous ORFs within introns and with their preferred location (at least in yeast) at the $5^{\prime}$ ends of genes (Fink 1987). The UPF1 and NMD2 gene products thus function as part of an mRNA surveillance system that degrades nonsense-containing transcripts, possibly to ensure that aberrant proteins do not accumulate in the cell. A similar conclusion has been drawn about the $C$. elegans smg gene products (Pulak and Anderson 1993). Other experiments have shown these gene products are also involved in the regulation of decay rates in transcripts with upstream ORFs, the regulation of translational frameshifting, and the suppression of out-of-frame ATG insertions upstream of normal translational initiation sites (Cui et al., this issue; Peltz et al. 1994; Y. Weng, K. Czaplinski, and S. Peltz, in prep.). What, then, is the likely function of these factors? A working model of the decay mechanism, based on work in several laboratories (Hsu and Stevens 1993; Peltz and Jacobson 1993; Peltz et al. 1993, 1994; Muhlrad and Parker 1994; E. Welch and A. Jacobson, in prep.) suggests that, after termination at a nonsense codon, the small ribosomal subunit scans downstream until it encounters a sequence favorable for translational reinitiation and that the reinitiation event triggers entry into the mRNA decapping and $5^{\prime} \rightarrow 3^{\prime}$ exonucleolytic decay pathway. Taking into account the fact that mutations in UPF1 and NMD2 have no effects on normal mRNAs, such a model suggests that Nmd2p and Upflp could be factors that are involved in determining the efficiency of 
translational termination or reinitiation or factors involved in the initial assembly of an initiation- and termination-competent mRNP. Mutational analyses of these two gene products, currently in progress, are likely to provide additional insight into their respective functions.

\section{Materials and methods}

Yeast strains, growth conditions, and cell manipulation procedures

Yeast strains used in this study are listed in Table 1. GGY1::171 (Gill and Ptashne 1987) and W303 (Thomas and Rothstein 1989) have been described previously. HFY1000, a diploid strain heterozygous for $N M D 2$, was constructed by transformation of W303 with a SacI-SalI fragment of the deletion-disruption nmd2::HIS3 allele from Bs-nmd2::HIS3 (see Plasmids). HFY1100, HFY1200, HFY1300, and HFY 1400 are haploid progeny strains from one tetrad of HFY1000. HFY1201-1206 and
HFY1301-1306 were constructed by transformation of HFY 1200 and HFY 1300 with each of the six plasmids harboring the nonsense-containing PGK1 alleles described previously (Peltz et al. 1993). HFY2000 is the same as HFY1300 except that it also contains the temperature-sensitive $r p b 1-1$ allele (Nonet et al. 1987). HFY2000 was constructed by integrative transformation of HFY1300 (YIp5-RPB1-1U containing the $r p b 1-1$ allele on a 5.8 -kb EcoRI-HindIII fragment was linearized with $X b a \mathrm{I}$ within the insert and targeted to the $R P B 1$ locus). Ura ${ }^{+}$transformants were selected, grown in rich medium, and then plated on media containing 5-fluoro-orotic acid (5-FOA) to select for recombinant events leading to excision of the duplicated DNA sequences (Boeke et al. 1987). Temperature-sensitive colonies were identified and tested for transcriptonal inhibition of RNA polymerse II at $36^{\circ} \mathrm{C}$ by Northern analysis. HFY2106 and HFY2206 were constructed by cotransformation of HFY2000 with either pRS315 or pRS315-NMD2(X-S) and a plasmid harboring a $P G K 1$ allele with a nonsense mutation at the BglII site (Peltz et al. 1993). HFY2301-2305 plasmids were constructed by transformation of pRS315, pRS315-NMD2(X-S), pRS315F1-NMD2(X-S), pRS315-F2-NMD2(X-S), or pRS315-MYC-

Table 1. Yeast strains

\begin{tabular}{|c|c|c|}
\hline Strain & Genotype & Source \\
\hline GGY1::171 & $\Delta$ gal4 $\Delta$ gal80 URA3::GAL1-lacZ his3 leu2 & Stanley Fields \\
\hline W303 & $\begin{array}{l}\text { MATa/MAT } \alpha \text { ade2-1/ade2-1 his3-11,15/his3-11,15 leu2-3,112/leu2-3,112 trp1-1/trp1-1 } \\
\text { ura3-1/ura3-1 can1-100/can1-100 }\end{array}$ & Duane Jenness \\
\hline HFY 1000 & $\begin{array}{l}\text { MATa/MAT a ade2-1/ade2-1 his3-11,15/his3-11,15 leu2-3,112/leu2-3,112 trp1-1/trp1-1 } \\
\text { ura3-1/ura3-1 can1-100/can1-100 nmd2::HIS3/NMD2 }\end{array}$ & this study \\
\hline HFY 1100 & MAT $\alpha$ ade2-1 his3-11,15 leu2-3,112 trp1-1 ura3-1 can1-100 NMD2 & this study \\
\hline HFY1200 & MATa ade2-1 his3-11,15 leu2-3,112 trp1-1 ura3-1 can1-100 NMD2 & this study \\
\hline HFY1300 & MAT $\alpha$ ade2-1 his3-11,15 leu2-3,112 trp1-1 ura3-1 can1-100 nmd2::HIS3 & this study \\
\hline HFY 1400 & MATa ade2-1 his3-11,15 leu2-3,112 trp1-1 ura3-1 can1-100 nmd2::HIS3 & this study \\
\hline HFY1201 & same as HFY 1200 but containing [pRIPPGKH2 |3| UAG] & \\
\hline HFY1202 & same as HFY 1200 but containing [pRIPPGKAsp UAG] & this study \\
\hline HFY1203 & same as HFY 1200 but containing [pRIPPGKH2 (2) UAG] & this study \\
\hline HFY1204 & same as HFY 1200 but containing [pRIPPGKH 2 (1) UAG] & this study \\
\hline HFY 1205 & same as HFY1200 but containing [pRIPPGKXba UAG] & this study \\
\hline HFY1206 & same as HFY1200 but containing [pRIPPGKBgl UAG] & this study \\
\hline HFY1301 & same as HFY 1300 but containing [pRIPPGKH2 (3) UAG] & this study \\
\hline HFY 1302 & same as HFY1300 but containing [pRIPPGKAsp UAG] & this study \\
\hline HFY 1303 & same as HFY 1300 but containing [pRIPPGKH2 (2) UAG] & this study \\
\hline HFY 1304 & same as HFY 1300 but containing [pRIPPGKH2 (1) UAG] & this study \\
\hline HFY1305 & same as HFY1300 but containing [pRIPPGKXba UAG] & this study \\
\hline HFY 1306 & same as HFY1300 but containing [pRIPPGKBgl UAG] & this study \\
\hline HFY 1307 & same as HFY 1300 but containing [YEplac1 12] & this study \\
\hline HFY1308 & same as HFY1300 but containing [YEplac112-NMD2 (X-S)] & this study \\
\hline HFY1309 & same as HFY 1300 but containing [YEplac1 12-F2-NMD2 (X-S)] & this study \\
\hline HFY 1310 & same as HFY1300 but containing [YEplac112-HA-NMD2 (X-S)] & this study \\
\hline HFY2000 & MAT $\alpha$ ade2-1 his3-11,15 leu2-3,112 trp1-1 ura3-1 can1-100 rpb1-1 nmd2::HIS3 & this study \\
\hline HFY2106 & same as HFY2000 but containing [pRS315] [pRIPPGKBgl UAG] & this study \\
\hline HFY2206 & same as HFY2000 but containing [pRS315-NMD2 (X-S)] [pRIPPGKBgl UAG] & this study \\
\hline HFY2301 & same as HFY2000 but containing [pRS315] & this study \\
\hline HFY2302 & same as HFY2000 but containing [pRS315-NMD2 (X-S)] & this study \\
\hline HFY2303 & same as HFY2000 but containing [pRS315-F1-NMD2 (X-S)] & this study \\
\hline HFY2304 & same as HFY2000 but containing [pRS315-F2-NMD2 (X-S)] & this study \\
\hline HFY2305 & same as HFY2000 but containing [pRS315-MYC-NMD2 (X-S)] & this study \\
\hline HFY3000 & MAT $\alpha$ ade2-1 his3-11,15 leu2-3,112 trp1-1 ura3-1 can1-100 nmd2::HIS3 upf $1::$ URA3 & this study \\
\hline HFY3001 & same as HFY3000 but containing [pRS315] [pRS314] & this study \\
\hline HFY3002 & same as HFY3000 but containing [pRS315-NMD2 (X-S1] [pRS314-UPF1] & this study \\
\hline HFY3005 & same as HFY2000 but containing [pRS315-NMD2 (X-S)] [pRS314] & this study \\
\hline HFY3008 & same as HFY2000 but containing [pRS315] [pRS314-UPF1] & this study \\
\hline
\end{tabular}


NMD2(X-S) into HFY2000. HFY3000, an nmd2::HIS3 and upf $1:: U R A 3$ double mutant, was constructed by transforming HFY 1300 with an EcoRI-BamHI fragment of the deletion-disruption upf1::URA3 allele from pGEM-upf1::URA3.

Preparation of standard yeast media, cell culture, sporulation, and tetrad analysis were carried out according to Rose et al. (1990). Transformation with plasmid-borne cloned genes was performed by the method of Schiestl and Gietz (1989). $\beta$-Galactosidase activity was assayed by replica-plating on SSX plates (Chien et al. 1991). SSX medium contained 6.7 grams of yeast nitrogen base, 30 grams of agar, $40 \mathrm{mg}$ of $\beta$-D-4-chloro-3-indolylD- $\beta$-galactosidase (X-gal), $100 \mathrm{ml}$ of $1 \mathrm{M}$ potassium phosphate (pH 7.0), $100 \mathrm{ml}$ of $20 \%$ (wt/vol) sucrose, $100 \mathrm{ml}$ of $10 \times$ amino acids minus leucine and histidine, and $\mathrm{H}_{2} \mathrm{O}$ to 1 liter.

\section{Plasmids}

Plasmid libraries containing yeast genomic DNA fragments fused to the GAL4 transcriptional activation domain /Chien et al. 1991) and plasmids pGAD1F, pGAD2F, and pMA424-LAM5 were generous gifts from Stanley Fields and Paul Bartel (State University of New York, Stony Brook). The plasmid pMA424 CEP1 was obtained from Richard Baker (University of Massachusetts Medical Center, Worcester). pRPB1-1U, which harbors the rpb1-1 temperature-sensitive allele, was obtained from Richard Young (Whitehead Institute, Massachusetts Institute of Technology, Cambridge). The following plasmids were also used in this study: Bluescript $\mathrm{KS} \mid+1$, an Escherichia coli cloning vector (Stratagene); YIp5, a yeast integrative plasmid containing the URA3 gene (Botstein and Davis 1982); pRS314 and pRS315, yeast shuttle plasmids containing $A R S 4$ and CEN6 and either the TRP1 gene (314) or the LEU2 gene (315) (Sikorski and Hieter $1989)$; and YEplac1 12, a yeast $2 \mu$ vector containing the TRP1 gene (Gietz and Sugino 1988). The names and genotypes of plasmids constructed in this study are listed in Table 2. pMA424 $U P F 1$, the GAL4 DNA-binding domain-UPF1 fusion plasmid, was constructed by a three-fragment ligation. A fragment of 144 bp from the initial ATG codon to the forty-eighth codon of UPF1 was amplified by PCR using UPF 1-TH-5' and UPF1-TH-3' as oligonucleotide primers /amplification with these primers led to the introduction of an EcoRI site adjacent to the initiator ATG). The PCR-amplified fragment was digested with EcoRI and $B s t \mathrm{XI}$ and ligated with a $B s t \mathrm{XI}-\mathrm{BamHI}$ fragment [including the rest of the UPF1-coding region and $\sim 1 \mathrm{~kb} 3^{\prime}$ distal to the translational termination site including the entire $3^{\prime}$-untranslated region (UTR)] into plasmid pMA424 digested by EcoRI and $B a m H I$. DNA sequence analysis was used to confirm the primary structure of the construct. Bs-F1-NMD2(Bg-H) was also constructed by a three-fragment ligation. A 635-bp PCR-derived $B g I I I-N c o l$ fragment containing the promoter and $5^{\prime}$-UTR of NMD2 and a 386-bp PCR-derived NcoI-HindIII fragment (from the ATG in the intron to the unique HindIII site in the coding region of $N M D 2$ ) were ligated into Bluescript digested previously by BamHI and HindIII. The oligonucleotide primers NMD2-1 and NMD2-10, NMD2-F1, and NMD2-7 were used for PCR amplification of both fragments, respectively. Amplification with these primers led to the creation of an Ncol site at the position of the ATG in the intron and the introduction of the FLAG-epitope sequence immediately downstream. DNA sequencing was used to confirm the structure of the construct. Bs-F2-NMD2(Bg-H) was constructed in the same way as Bs-F1NMD2(Bg-H) except that the Ncol site and FLAG-epitope sequence were introduced at the site of the initial ATG codon of NMD2. The Ncol and FLAG-epitope tag containing primers used were NMD2-15 and NMD2-F2. Bs-MYC-NMD2(Bg-H) was constructed in the same way as Bs-F2-NMD2(Bg-H) except that the c-myc-epitope sequence was used. The NcoI and c-mycepitope tag containing primer was NMD2-MYC. Bs-HANMD2(Xh-H) was constructed as follows: First, a 119-bp XbaI/ NcoI-Xhol/EcoRI fragment containing a triple repeat of the HA epitope (Field et al. 1988) was cloned into pBluescript in which the XhoI site had been eliminated by filling in with Klenow enzyme (the sequence of this fragment is 5'-TCTAGACCATGGAGTACCCATACGATGTTCCTGACTATGCGGGCTATCCCTATGACGTCCCGGACTATGCAGGATCCTATCCATATGACGTTCCAGATTACGCTAGCCTCGAGGAATCC- $3^{\prime}$ \% Subsequently, a 473-bp XhoI-HindIII fragment, from the second codon of NMD2 to the unique HindIII site in the NMD2-coding region, was amplified by $\mathrm{PCR}$ (with oligonucleotide primers NMD2-HA and NMD2-7) and cloned into the XhoI and HindIII sites downstream of the HA epitope sequences. Plasmids used to assess the consequences of $\mathrm{Nmd} 2 \mathrm{p}$ overexpression were derived from pGAD2-NMD2. The $6.0-\mathrm{kb}$ HindIII fragment of this plasmid encodes the first five amino acids of SV40 T antigen, the 12 amino acid NLS from $T$ antigen, amino acids $11-34$ from T7 RNA polymerase, amino acids $768-881$ from the $G A L 4$ activation domain, and a segment of $\mathrm{Nmd} 2 \mathrm{p}$ that extends from amino acid 326 to the carboxyl terminus of the protein. To generate the NLS deletion of this protein, the HindIII fragment was subcloned into pBluescript in which the EcoRI site had been destroyed by filling in with Klenow enzyme. The resulting plasmid was cut with EcoRI, generating a 36-bp fragment lencoding the NLS), a 1.9-kb fragment (sequences encoding $\mathrm{T} 7$ RNA polymerase, GAL4 activation domain, and part of $\mathrm{Nmd} 2 \mathrm{p}$ ), and a 7.0-kb fragment (encoding the rest of $\mathrm{Nmd} 2 \mathrm{p}$, vector, and SV40 sequences). The latter two fragments were religated, recreating the original fusion protein gene lacking the sequences encoding the NLS. The original, and the NLS-deleted, $6.0-\mathrm{kb} H$ indIII fragments were then used to replace the $0.6-\mathrm{kb}$ HindIII fragment of pGAD2F in both orientations such that transcription of one pair of constructs was driven by the $A D H 1$ promoter (pGAD2F-NMD2-ADH $H_{\mathrm{p}}$ and pGAD2F$\left.N M D 2-A D H_{\mathrm{p}}-\Delta N L S\right)$ and transcription of the other pair was driven by sequences within the $A D H 1$ terminator (pGAD2F$N M D 2-A D H_{\mathrm{t}}$ and pGAD2F-NMD2-ADH $\left.H_{\mathrm{t}}-\Delta \mathrm{NLS}\right)$.

\section{Oligonucleotides}

The oligonucleotides used in this study were obtained from Operon, Inc. and are listed in Table 3.

\section{Two-hybrid screening}

The yeast strain GGY1::171 was cotransformed with both pMA424-UPF1 and one of the libraries containing genomic DNA fragments fused to the GAL4 activation domain. After 3-4 days growth on SD-His-Leu plates at $30^{\circ} \mathrm{C}$, $\mathrm{His}^{+} \mathrm{Leu}^{+}$transformants were replica-plated to SSX plates and were incubated until blue colonies appeared. False-positive colonies resulting from cloning of the GAL4 gene into the pGAD vectors were eliminated by PCR of yeast cells with the GAL4-specific primers GAL4-5' (from nucleotide 1206 to 1229) and GAL4-3' (from nucleotide 2552 to 2528) (Laughon and Gesteland 1984). Cells from the remaining blue colonies were grown in SD-Leu medium, and plasmids were recovered and transformed into the $E$. coli strain MH6 by electroporation. The activation domain (pGAD) plasmids from the library were identified by their ability to complement an $E$. coli $\operatorname{leu} B$ mutation as a result of the presence of the plasmid-borne $L E U 2$ gene. To confirm that transcriptional activation was dependent on the presence of both 
Table 2. Plasmids

\begin{tabular}{|c|c|}
\hline Plasmids & Relevant yeast sequences \\
\hline pMA424-UPF1 & $\begin{array}{l}\text { 3.6-kb EcoRI-BamHI fragment containing the entire UPF1-coding region and } \sim 1.0-\mathrm{kb} \\
\text { downstream sequences cloned into the EcoRI-BamHI sites of pMA424 }\end{array}$ \\
\hline pRS314-UPF1 & 4.2-kb EoRI-BamHI fragment containing the entire UPF1 in pRS314 \\
\hline pGEM-upf1::URA3 & $\begin{array}{l}\text { UPF1 disruption plasmid containing a } 1.1-\mathrm{kb} \text { EcoRI-EcoRV fragment from the } 5^{\prime} \text { end of UPF1, } \\
\text { a } 1.2-\mathrm{kb} \text { SmaI-HindIII fragment of URA3, and a } 2.0-\mathrm{kb} \text { HindIII-BamHI fragment from the } 3 \text { ' } \\
\text { end of UPF1 in pGEM-4Z }\end{array}$ \\
\hline Yip5-RPB1-1U & 5.8-kb EcoRI-HindIII fragment containing $r p b 1-1$ allele cloned into YIp5 \\
\hline pGAD2-NMD2 & $\begin{array}{l}5.3-\mathrm{kb} \text { genomic DNA fragment fused to GAL4 activation domain in pGAD2, the fusion begins } \\
\text { at codon } 326 \text { in the NMD2-coding region }\end{array}$ \\
\hline Ycp50-NMD2 & 12-kb genomic DNA insert containing the entire $N M D 2$ gene in $\mathrm{YCp} 50$ \\
\hline Bs-F1-NMD2(Bg-H) & $\begin{array}{l}\text { 998-bp BglII-HindIII fragment containing the NMD2 promoter region and } 5 \text { '-coding region } \\
\text { cloned into BamHI and HindIII of Bluescript with FLAG-epitope sequence introduced } \\
\text { adjacent to the ATG in the NMD2 intron }\end{array}$ \\
\hline Bs-F2-NMD2(Bg-H) & $\begin{array}{l}\text { 998-bp BglII-HindIII fragment containing the NMD2 promoter region and } 5 \text { '-coding region } \\
\text { cloned into the BamHI and HindIII of Bluescript with the FLAG-epitope sequence was } \\
\text { introduced adjacent to the initial ATG codon of NMD2 }\end{array}$ \\
\hline Bs-MYC-NMD2(Bg-H) & $\begin{array}{l}\text { 998-bp BglII-HindIII fragment containing the NMD2 promoter region and } 5 \text { '-coding region } \\
\text { cloned into the BamHI and HindIII of Bluescript with the } M Y C \text {-epitope sequence introduced } \\
\text { adjacent to the initial ATG codon of NMD2 }\end{array}$ \\
\hline Bs-HA-NMD2(Xh-H) & $\begin{array}{l}\text { 574-bp NcoI-HindIII fragment containing a triple HA-epitope tag and NMD2 sequences from } \\
\text { the second codon to the unique HindIII site }\end{array}$ \\
\hline Bs-nmd2::HIS3 & $\begin{array}{l}\text { NMD2 disruption plasmid containing a } 0.6-\mathrm{kb} C l a \mathrm{I}-X \mathrm{baI} \text { fragment in the } 5^{\prime} \text { end of } N M D 2 \text {, a } \\
1.7-\mathrm{kb} \mathrm{XbaI}-\mathrm{Clal} \text { fragment of HIS } 3 \text { and a } 1.2-\mathrm{kb} C \mathrm{Cl} \text { I-EcoRI fragment in the NMD2-coding } \\
\text { region in Bluescript }\end{array}$ \\
\hline pRS315-NMD2(C5'-C3') & 2.3-kb ClaI $\left(5^{\prime}\right)-C l a I\left(3^{\prime}\right)$ fragment of the $5^{\prime}$ end of $N M D 2$ in pRS3 15 \\
\hline pRS315-NMD2-1/C & $3.5-\mathrm{kb}$ ClaI $\left(3^{\prime}\right)-$ Sall fragment of the $3^{\prime}$ end of $I$ \\
\hline pRS315-NMD2 $\left(\mathrm{C5}^{\prime}-\mathrm{P}\right)$ & 3.4-kb ClaI $\left(5^{\prime}\right)-P s t I$ fragment of the $5^{\prime}$ end of NMD2 in pRS315 \\
\hline pRS315-NMD2(X-P) & 2.8-kb Xbal-PstI fragment of the $5^{\prime}$ end of NMD2 in pRS315 \\
\hline pRS315-NMD2-2(C5'-S) & 5.8-kb ClaI $\left(5^{\prime}\right)-S a l \mathrm{I}$ fragment of $N M D 2$ in pRS315 \\
\hline pRS315-NMD2(X-S) & $5.2-\mathrm{kb} X b a \mathrm{I}-$ Sall fragment of NMD2 in pRS315 \\
\hline pRS315-F1-NMD2(X-S) & $\begin{array}{l}\text { same as pRS315-NMD2(X-S) except that a FLAG-epitope tag sequence was inserted } \\
\text { downstream of the ATG in the intron of NMD2 }\end{array}$ \\
\hline pRS315-F2-NMD2(X-S) & $\begin{array}{l}\text { same as pRS315-NMD2(X-S) except that FLAG-epitope tag sequence was inserted downstream } \\
\text { of the initial ATG codon of NMD2 }\end{array}$ \\
\hline pRS315-MYC-NMD2(X-S) & $\begin{array}{l}\text { same as pRS315-NMD2(X-S) except that } M Y C \text {-epitope tag sequence was inserted downstream } \\
\text { of the initial ATG codon of NMD2 }\end{array}$ \\
\hline pRS315-HA-NMD2(X-S) & $\begin{array}{l}\text { same as pRS315-NMD2|X-S| except that the triple HA-epitope tag sequence was inserted } \\
\text { downstream of the initial ATG codon of NMD2 }\end{array}$ \\
\hline YEplac1 12-NMD2(X-S) & NMD2 XbaI-SalI fragment from pRS315-NMD2(X-S) cloned into YEplac1 12 \\
\hline YEplacl 12-F2NMD2(X-S) & F2-NMD2 XbaI-SalI fragment from pRS315-F2-NMD2(X-S) cloned into YEplacl 12 \\
\hline YEplac 112-HA-NMDS(X-S) & HA-NMD2 XbaI-SalI fragment from pRS315-HA-NMD2(X-S) cloned into YEplac1 12 \\
\hline pGADIF-NMD2- $\Delta 1$ & $\begin{array}{l}\text { 1872-bp PCR-derived BamHI-BglII fragment encoding carboxy-terminal } 526 \text { amino acids and } \\
183 \text { bp of } 3 \text {-untranslated region of NMD2 cloned into the BamHI site of pGADIF }\end{array}$ \\
\hline pGAD1F-NMD2- $\Delta 2$ & $\begin{array}{l}\text { 1041-bp PCR-derived BamHI-BglII fragment encoding carboxy-terminal } 286 \text { amino acids and } \\
183 \mathrm{bp} \text { of } 3^{\prime} \text {-untranslated region of NMD2 cloned into the BamHI site of pGADIF }\end{array}$ \\
\hline pGAD1F-NMD2- $\Delta 3$ & $\begin{array}{l}\text { 711-bp PCR-derived BamHI-BglII fragment encoding } 237 \text { amino acids from codon } 326 \text { to } 563 \text { of } \\
\text { NMD2 cloned into the BamHI site of pGADIF }\end{array}$ \\
\hline pGAD1F-NMD2- $\Delta 4$ & $\begin{array}{l}\text { 1434-bp PCR-derived BamHI-BglII fragment encoding } 477 \text { amino acids from codon } 326 \text { to } 803 \\
\text { of NMD2 cloned into the BamHI site of pGAD1F }\end{array}$ \\
\hline pGAD2F-NMD2-ADHp & $\begin{array}{l}\text { 6.0-kb HindIII-HindIII fragment from pGAD2-NMD2 replaced the } 0.6-\mathrm{kb} \text { HindIII-HindIII } \\
\text { fragment of pGAD2F such that the expression of the } G A L 4 \text { activation domain-NMD2 fusion } \\
\text { was driven by the } A D H 1 \text { promoter }\end{array}$ \\
\hline pGAD2F-NMD2-ADHt & $\begin{array}{l}\text { 6.0-kb HindIII-HindIII fragment from pGAD2-NMD2 replaced the } 0.6-\mathrm{kb} \text { HindIII-HindIII } \\
\text { fragment of pGAD2F such that the expression of the GAL4 activation domain-NMD2 fusion } \\
\text { was driven by the } A D H 1 \text { terminator }\end{array}$ \\
\hline pGAD2F-NMD2-ADHp- $\Delta$ NLS & $\begin{array}{l}\text { same as pGAD2F-NMD2-ADHp except that the SV } 40 \text { nuclear localization signal of the fusion } \\
\text { protein was deleted }\end{array}$ \\
\hline pGAD2F-NMD2-ADHt- $-\Delta$ NLS & $\begin{array}{l}\text { same as pGAD2F-NMD2-ADHt except that the SV40 nuclear localization signal of the fusion } \\
\text { protein was deleted }\end{array}$ \\
\hline
\end{tabular}


Table 3. Oligonucleotides

\begin{tabular}{ll}
\hline Name & Sequences \\
\hline UPFl-TH-5' & 5'-CCGGAATTCATGGTCGGT TCCGGTTCT-3' \\
UPFl-TH-3' & 5'-AGTGACT TGAGCCTC-3' \\
GAL4-5' & 5'-GCCCTATCGTGCACTCACCGACGC-3' \\
GAL4-3' & 5'-GTGAAGGCCCT ACTGAGCCAGGAG-3' \\
NMD2-1 & 5'-ATGATTGCAGTCAGAGGCCACAC-3' \\
NMD2-5 & 5'-ACTT TTCAGGGGAAAGACTTC-3' \\
NMD2-7 & 5'-AACAGAGGGGTTCTCAAAAGC-3' \\
NMD2-10 & 5'-GACTCCATGGTTGTTACCGTAGTTTACA-3' \\
NMD2-13 & 5'-CTGTTGATACATAATTGTTAC-3' \\
NMD2-14 & 5'-CAATTCTTTTTTCGTCCATC-3' \\
NMD2-15 & 5'-GACTCCATGGTTTCTGTCCAATGTATTATCAATG-3' \\
NMD2-HA & 5'-GCCGCTCGAGGACGTATGTTTGATTTATCTT-3' \\
NMD2-F1 & 5'-GACTCCATGGATTACAAGGACGACGATGACAAGATGT ATCAACAGGATGGACGGAAA-3' \\
NMD2-F2 & 5'-GACTCCATGGATTACAAGGACGACGATGACAAGATGGACGTATGTTTGATTTATCTT-3' \\
NMD2-MYC & 5'-GACTCCATGGAGCAGAAGCTGATTAGCGAGGAAGATCTGAATATGGACGTATGTTTGATTTAT \\
& CTT-3' \\
\hline
\end{tabular}

gene fusions, the isolated library plasmids were retransformed into the original GGY1::171 strain with either (1) the pMA424 UPF1 fusion, (2) pMA424, the GAL4 DNA-binding domain vector only, (3) an unrelated fusion, pMA424-CEP1, or $(4)$ an unrelated pMA424-LAM5 fusion. Plasmids that yielded blue colonies only with the pMA424-UPF1 fusion were characterized further by restriction mapping, Southern blotting, and sequence analysis. DNA sequences were compared to existing sequence databases using the FASTA program (Devereux et al. 1984).

\section{DNA sequencing}

DNA sequences were determined by the method of Sanger et al. (1977). Overlapping fragments of the NMD2 gene were subcloned in Bluescript and sequenced by annealing of oligonucleotide primers specific to the $\mathrm{T} 3$ or $\mathrm{T} 7$ promoter regions of the plasmid or by use of oligonucleotide primers that annealed within the subcloned inserts.

\section{Transcript mapping}

Primer extension analysis was performed according to the procedure described by Boorstein and Craig (1989). Total RNAs from W303 (wild-type, NMD2/NMD2) and HFY1300 (deletiondisruption, nmd2::HIS3) were hybridized to oligonucleotide primers complementary to the NMD2 sense strand at the following positions: 99-119 (oligonucleotide NMD2-13); 120-140 (oligonucleotide NMD2-14); and 174-194 (oligonucleotide NMD2-5), respectively.

\section{Southern blot analysis}

Total yeast genomic DNA was extracted according to the method of Holm et al. (1986). After restriction digestion, DNA was electrophoresed on $0.8 \%$ agarose gels, transferred, and cross-linked to Zetaprobe membranes as described in Sambrook et al. (1991). Filters were prehybridized $2-3 \mathrm{hr}$ at $42^{\circ} \mathrm{C}$ in $5 \times$ SSPE, $40 \%$ formamide, $5 \times$ Denhardt's solution, $0.1 \%$ SDS, and $4 \mathrm{mg} / \mathrm{ml}$ of salmon sperm DNA. A radiolabeled NMD2 probe (1.2-kb Clal-EcoRI fragment), generated by random priming, was added and filters were hybridized overnight at $42^{\circ} \mathrm{C}$. Filters were washed twice in $1 \times \mathrm{SSC}, 0.1 \% \mathrm{SDS}$, at room temperature and once in $0.1 \times \mathrm{SSC}, 0.1 \% \mathrm{SDS}$, at $58^{\circ} \mathrm{C}$ before analysis on a Betagen Blot Analyzer.

Isolation of the NMD2 genomic DNA clone and disruption of the chromosomal NMD2 and UPF1 genes

A S. cerevisiae genomic DNA library of Sau3A partial fragments constructed in YCp50 was provided by M. Rose (Rose et al. 1987). Colony hybridization was performed as described in Sambrook et al. (1991) under the same conditions described for the genomic DNA Southern hybridization. Approximately three genomic equivalents were screened. Disruption of the NMD2 gene (Rothstein 1991) was performed by transformation of the diploid strain W303 with a SacI-SalI fragment from Bsnmd2::HIS3 (the SacI and SalI sites are in the Bluescript polylinker; see Plasmids) and selecting $\mathrm{His}^{+}$transformants. The disruption event was confirmed by Southern analysis. Sporulation and tetrad analysis yielded haploid strains containing nmd2::HIS3 disruptions. The UPF1 gene disruption was performed by tranforming the haploid strain HFY1300 with a EcoRI-BamHI fragment from the plasmid pGEM-upf1::URA3. $\mathrm{Ura}^{+}$transformants were selected, and the disruption event was confirmed by Southern analysis.

\section{Mapping of the NMD2 locus}

The $12-\mathrm{kb}$ insert of yeast DNA in YCp50-NMD2 was mapped with different restriction enzymes, and the location of the NMD2 gene was determined by comparison of the restriction map of this insert with that of pGAD2-NMD2. To obtain the smallest functional clone, different fragments from the NMD2 region were isolated, subcloned into the pRS315 vector, transformed into HFY 1300 (which contains a partial deletion of the chromosomal NMD2 gene|, and suppression of nonsense-mediated mRNA decay was assessed by measurement of the abundance of the CYH2 pre-mRNA by Northern analysis (see Fig. $2 \mathrm{Cl}$. To obtain a physical map position for the chromosomal NMD2 gene, a 1.7-kb XbaI-ClaI fragment of NMD2 was hybridized to filters containing DNA from a set of mapped and characterized PrimeClones (from ATCC) from the genome of $S$. cerevisiae AB972 (ATCC 76269). The conditions of hybridization 
and washing were the same as described for Southern hybridization.

\section{mRNA decay measurements, RNA preparation, and Northern analysis}

mRNA decay rates were measured as described previously (Herrick et al. 1990; Parker et al. 1991; Peltz et al. 1993). For measurement of mRNA abundance, yeast cells $(20 \mathrm{ml})$ were grown to an $\mathrm{OD}_{600}$ of $0.5-0.7$ at $24^{\circ} \mathrm{C}$, spun down, resuspended in $4 \mathrm{ml}$ of the same medium, and incubated at $24^{\circ} \mathrm{C}$ for $30 \mathrm{~min}$. An aliquot $(2 \mathrm{ml})$ of concentrated cell culture was collected and frozen quickly on dry ice. Total yeast RNA was isolated as described previously (Herrick et al. 1991). For both decay rate measurements and abundance measurements equal amounts (usually $20 \mu \mathrm{g}$ ) of total RNA from each sample were analyzed by Northern blotting, generally with probes labeled in random priming reactions. Hybridization conditions for such blots were as described for genomic Southern hybridization. When oligonucleotide probes were used, the hybridization conditions were those described by Peltz et al. (1993). Northern blots were quantitated with a Betagen Blot Analyzer (Herrick et al. 1990). mRNA decay data are expressed as the $\log _{10}$ of the percentage of each RNA remaining versus time at $36^{\circ} \mathrm{C}$.

\section{Western blot analysis}

Yeast whole-cell extracts were prepared by resuspension of cells at $3 \mathrm{OD}_{600}$ equivalents $/ 100 \mu \mathrm{l}$ in blue-urea mix buffer $(1 \mathrm{ml}$ of $17.5 \mathrm{~mm}$ Tris- $\mathrm{HCl}$ at $\mathrm{pH} 6.8,1.75 \%$ SDS, $100 \mu \mathrm{l}$ of $\beta$-mercaptoethanol, 1 gram of urea, and $0.01 \%$ bromophenol blue), vortexing with glass beads for $2 \mathrm{~min}$ at $4^{\circ} \mathrm{C}$, and clarification by brief centrifugation. After SDS-PAGE, proteins were transferred electrophoretically to Immobilon-P membranes (Millipore). Antibody incubation was carried out in PBS $\left(80 \mathrm{mM} \mathrm{Na}_{2} \mathrm{HPO}_{4}, 20\right.$ $\mathrm{mM} \mathrm{NaH}_{2} \mathrm{PO}_{4}, 100 \mathrm{~mm} \mathrm{NaCl}$ ) and $1 \%$ dried milk at room tem. perature for $60 \mathrm{~min}$. Anti-FLAG monoclonal antibody (M5; 1.2 $\mathrm{mg} / \mathrm{ml}$; a generous gift from Immunex Research and Development Corp., Seattle, WA) and anti-MYC monoclonal antibody (9E10; $0.1 \mathrm{mg} / \mathrm{ml}$; Santa Cruz Biotechnology) were diluted 1: 1000 and 1:1000, respectively. Horseradish peroxidase-conjugated goat anti-mouse $\operatorname{IgG}+\operatorname{IgM}(\mathrm{H}+\mathrm{L})$ was diluted $1: 1000$. Bound antibodies were detected with the ECL system /Amersham) used according to the manufacturer's instructions.

\section{Acknowledgments}

This work was supported by a grant to A.J. from the National Institutes of Health (GM27757) and by a postdoctoral fellowship to F.H. from the Charles A. King Trust, Fleet Bank, Boston, MA. We are especially indebted to Stan Fields and Paul Bartel for generously providing plasmids, strains, libraries, and advice. We are also grateful to Agneta Brown for technical assistance, Rick Baker, Duane Jenness, and Rick Young for strains and plasmids, Andrew Bond, Agneta Brown, Robin Ganesan, Aidan Hennigan, David Mangus, Ellen Welch, and Dorit Zuk for helpful comments on the manuscript, Stuart Peltz for communicating results prior to publication, Pam Silver for discussions about NLSs, and Immunex Research and Development Corp. for antiFLAG monoclonal antibodies.

The publication costs of this article were defrayed in part by payment of page charges. This article must therefore be hereby marked "advertisement" in accordance with 18 USC section 1734 solely to indicate this fact.

\section{References}

Altamura, N., O. Groudinsky, G. Dujardin, and P.P. Slonimski. 1992. NAM7 nuclear gene encodes a novel member of a family of helicase with a $\mathrm{Zn}$-ligand motif and is involved in mitochondrial functions in Saccharomyces cerevisiae. I. Mol. Biol. 224: 575-587.

Bartel, P., C.-T. Chien, R. Sternglanz, and S. Fields. 1993. Elimination of false positives that arise in using the two-hybrid system. BioTechniques 14: 920-924.

Baserga, S.J. and E.J. Benz Jr. 1992. $\beta$-Globin nonsense mutation: Deficient accumulation of mRNA occurs despite normal cytoplasmic stability. Proc. Natl. Acad. Sci. 89: 2935-2939.

Belgrader, P. and L.E. Maquat. 1994. Nonsense but not missense mutations can decrease the abundance of nuclear mRNA for the mouse major urinary protein, while both types of mutations can facilitate exon skipping. Mol. Cell. Biol. 14: 63266336.

Benton, B.M., W-K. Eng, J.J. Dunn, F.W. Studier, R. Sternglanz, and P.A. Fisher. 1990. Signal-mediated import of bacteriophage T7 RNA polymerase into the Saccharomyces cerevisiae nucleus and specific transcription of target genes. Mol. Cell. Biol. 10: 353-360.

Boeke, J.D., I. Trueheart, G. Natsoulis, and G.R. Fink. 1987. 5-Fluoroorotic acid as a selective agent in yeast molecular genetics. Methods Enzymol. 154: 164-175.

Boorstein, W.R. and E.A. Craig. 1989. Primer extension analysis of RNA. Methods Enzymol. 180: 347-369.

Botstein, D. and R.W. Davis. 1982. Principles and practice of recombinant DNA research with yeast. In The molecular biology of the yeast Saccharomyces cerevisiae leds. J.N. Strathern, E.W. Jones, and J.R. Broach). Cold Spring Harbor Laboratory, Cold Spring Harbor, New York.

Bourbon, H-M., B. Lapeyre, and F. Amalric. 1988. Structure of the mouse nucleolin gene: The complete sequence reveals that each RNA binding domain is encoded by two independent exons. I. Mol. Biol. 200: 627-638.

Cheng, J. and L.E. Maquat. 1993. Nonsense codons can reduce the abundance of nuclear mRNA without affecting the abundance of pre-mRNA or the half-life of cytoplasmic mRNA. Mol. Cell. Biol. 13: 1892-1902.

Cheng, I., P. Belgrader, X. Zhou, and L.E. Maquat. 1994. Introns are cis effectors of the nonsense-codon-mediated reduction in nuclear mRNA abundance. Mol. Cell. Biol. 14: 63176325.

Chien, C.-T., P.L. Bartel, R. Sternglanz, and S. Fields. 1991. The two hybrid system: A method to identify and clone genes for proteins that interact with a protein of interest. Proc. Natl. Acad. Sci. 88: 9578-9582.

Craigen, W.J., C.C. Lee, and C.T. Caskey. 1990. Recent advances in peptide chain termination. Mol. Microbiol. 4: 861865.

Cui, Y., K.W. Hagan, S. Zhang, and S. Peltz. 1995. Identification and characterization of genes that are required for the accelerated degradation of mRNAs containing a premature translational termination codon. Genes \& Dev. (this issue).

Culbertson, M.R., K.M. Underbrink, and G.R. Fink. 1980. Frameshift suppression in Saccharomyces cerevisiae. II. Genetic properties of Group II suppressors. Genetics 95: 833853.

Dang, Y.L. and N.C. Martin. 1993. Yeast mitochondrial RNase P. I. Biol. Chem. 268: 19791-19796.

Della Seta, F., I. Treich, J.M. Buhler, and A. Sentenac. 1990. ABF1 binding sites in yeast RNA polymerase genes. $/$. Biol. Chem. 265: 15168-15175.

DeMarini, D.J., M. Winey, D. Ursic, F. Webb, and M.R. Culbert- 
son. 1992. SEN1, a positive effector of tRNA-splicing endonuclease in Saccharomyces cerevisiae. Mol. Cell. Biol. 12: 2154-2164.

Devereux, J., P. Haeberli, and O. Smithies. 1984. A comprehensive set of sequence analysis programs for the VAX. Nucleic Acids Res. 12: 387-395.

Dingwall, C. and R.A. Laskey. 1991. Nuclear targeting sequences-A consensus? Trends Biochem. Sci. 16: 478-481.

Engebracht, J., K. Voelkel-Meiman, and G.S. Roeder. 1991. Meiosis-specific RNA splicing in yeast. Cell 66: 1257-1268.

Evan, G.I., G.K. Lewis, G. Ramsay, and M. Bishop. 1985. Isolation of monoclonal antibodies specific for human c-myc proto-oncogene product. Mol. Cell. Biol. 5: 3610-3616.

Field, J., J.-I. Nikawa, D. Broek, B. MacDonald, L. Rodgers, I.A. Wilson, R.A. Lerner, and M. Wigler. 1988. Purification of a $R A S$-responsive adenylyl cyclase complex from Saccharomyces cerevisiae by use of an epitope addition method. Mol. Cell. Biol. 8: 2159-2165.

Fields, S. 1993. The two-hybrid system to detect protein-protein interactions. Methods 5: 116-124.

Fields, S. and O.-K. Song. 1989. A novel genetic system to detect protein-protein interactions. Nature 340: 245-246.

Fields, S. and R. Sternglanz. 1994. The two-hybrid system: An assay for protein-protein interactions. Trends Genet. 10: 286-292.

Fink, G.R. 1987. Pseudogenes in yeast? Cell 49:5-6.

Gietz, R.D. and A. Sugino. 1988. New yeast-Escherichia coli shuttle vectors constructed with in vitro mutagenized yeast genes lacking six-base pair restriction sites. Gene 74: 527534.

Gill, G. and M. Ptashne. 1987. Mutants of Gal4 protein altered in an activation function. Cell 51: 121-126.

Gozalbo, D. and S. Hohmann. 1990. Nonsense suppressors partially revert the decrease of the mRNA level of a nonsense mutant allele in yeast. Curr. Genet. 17: 77-79.

He, F., S.W. Peltz, J.L. Donahue, and A. Jacobson 1993. Stabilization and ribosome association of unspliced pre-mRNAs in a yeast upf1 $1 \Delta$ mutant. Proc. Natl. Acad. Sci. 90: 7034-7039.

Herrick, D., R. Parker, and A. Jacobson. 1990. Identification and comparison of stable and unstable mRNAs in the yeast Saccharomyces cerevisiae. Mol. Cell. Biol. 10: 2269-2284.

Hisatake, K., T. Nishimura, Y. Maeda, K. Hanada, C.Z. Song, and M. Muramatsu. 1991. Cloning and structural analysis of cDNA and the gene for mouse transcription factor UBF. Nucleic Acids Res. 19: 4631-4637.

Holm, C., D.W. Meeks-Wagner, W.L. Fangman, and D. Botstein. 1986. A rapid, efficient method for isolating DNA from yeast. Gene 42: 169-173.

Hopp, T.P., K.S. Prickett, V.L. Price, R.T. Libby, C.J. March, P. Ceretti, D.L. Urdal, and P.J. Conlon. 1988. A short polypeptide marker sequence useful for recombinant protein identification and purification. Biotechnology 6: 1204-1210.

Hsu, C., and A. Stevens. 1993. Yeast cells lacking 5' to 3' exoribonuclease 1 contain mRNA species that are poly(A) deficient and partially lack the $5^{\prime}$ cap structure. Mol. Cell. Biol. 13: $4826-4835$.

Iggo, R.D., D.J. Jamieson, S.A. MacNeill, I. Southgate, J. McPheat, and D.P. Lane. p68 RNA helicase: Identification of a nucleolar form and cloning of related genes containing a conserved intron in yeasts. Mol. Cell. Biol. 11: 1326-1333.

Jantzen, H-M., A. Admon, S.P. Bell, and R. Tjian. 1990. Nucleolar transcription factor hUBF contains a DNA-binding motif with homology to HMG proteins. Nature 344: 830-836.

Koonin, E.V. 1992. A new group of putative RNA helicases. Trends Biochem. Sci. 17: 495-497.

Lapeyre, B., H. Bourbon, and F. Amalric. 1987. Nucleolin, the major nucleolar protein of growing eukaryotic cells: An unusual protein structure revealed by nucleotide sequence. Proc. Natl. Acad. Sci. 84: 1472-1476.

Laughon, A. and R.F. Gesteland. 1984. Primary structure of the Saccharomyces cerevisiae GAL4 gene. Mol. Cell. Biol. 4: 260-267.

Leeds, P., S.W. Peltz, A. Jacobson, and M.R. Culbertson. 1991. The product of the yeast UPF1 gene is required for rapid turnover of mRNAs containing a premature translational termination codon. Genes \& Dev. 5: 2303-2314.

Leeds, P., J.M. Wood, B.-S. Lee, and M.R. Culbertson. 1992. Gene products that promote mRNA turnover in Saccharomyces cerevisiae. Mol. Cell. Biol. 12: 2165-2177.

Link, A.J. and M.V. Olson. 1991. Physical map of the Saccharomyces cerevisiae genome at 110-kilobase resolution. Genetics 127: 681-698.

Losson, R. and F. Lacroute. 1979. Interference of nonsense mutations with eukaryotic messenger RNA stability. Proc. Natl. Acad. Sci. 76: 5134-5137.

Muhlrad, M. and R. Parker. 1994. Premature translational termination triggers mRNA decapping. Nature 370: 578-581.

Naeger, L.K., R. V. Schoborg, Q. Zhao, G.E. Tullis, and D.J. Pintel. 1992. Nonsense mutations inhibit splicing of MVM RNA in cis when they interrupt the reading frame of either exon of the final spliced product. Genes \& Dev. 6: 11071119.

Nonet, M., C. Scafe, J. Sexton, and R. Young. 1987. Eucaryotic RNA polymerase conditional mutant that rapidly ceases mRNA synthesis. Mol. Cell. Biol. 7: 1602-1611.

Olson, M.V., J.E. Dutchik, M.Y. Graham, G.M. Brodeur, C. Helms, M. Frank, M. Maccollin, R. Scheinman, and T. Frank. 1986. Random-clone strategy for genomic restriction mapping in yeast. Proc. Natl. Acad. Sci. 83: 7826-7830.

Ono, B-I., Y. Ishino-arao, M. Tanaka, I. Awano, and S. Shinoda. 1986. Recessive nonsense suppressors in Saccharomyces cerevisiae: Action spectra, complementation groups and map positions. Genetics 114: 363-374.

Osawa, S., T.H. Jukes, K. Watanable, and A. Muto. 1992. Recent evidence for evolution of the genetic code. Microbiol. Rev. 56: 229-264.

Parker, R., D. Herrick, S.W. Peltz, and A. Jacobson. 1991. Measurement of mRNA decay rates in Saccharomyces cerevisiae. Methods Enzymol. 194: 415-423.

Peltz, S.W. and A. Jacobson. 1993. mRNA turnover in Saccharomyces cerevisiae. In Control of mRNA stability led. G. Brawerman and J. Belascol, Academic Press, New York.

Peltz, S.W., A.H. Brown, and A. Jacobson. 1993. mRNA destabilization triggered by premature translational termination depends on at least three cis-acting sequence elements and one trans-acting factor. Genes \& Dev. 7: 1737-1754.

Peltz, W.S., F. He, E. Welch, and A. Jacobson. 1994. Nonsensemediated mRNA decay in yeast. Prog. Nucleic Acid Res. Mol. Biol. 47: 271-297.

Perentesis, I.P., L.D. Phan, W.B. Gleason, D.C. Laporte, D.M. Livingston, and J.W. Bodley. 1992. Saccharomyces cerevisiae elongation factor 2. I. Biol. Chem. 267: 1190-1197.

Pulak, R. and P. Anderson. 1993. mRNA surveillance by the Caenorhabditis elegans smg genes. Genes \& Dev. 7: 18851897.

Prickett, K.S., D.C. Amberg, and T.P. Hopp. 1989. A calciumdependent antibody for identification and purification of recombinant proteins. BioTechniques 7: 580-589.

Ramer, S.W., S.J. Ellege, and R.W. Davis. 1992. Dominant genetics using a yeast genomic library under the control of a strong inducible promoter. Proc. Natl. Acad. Sci. 89: 1158911593. 
Riles L., J.E. Dutchik, A. Baktha, B.K. McCauley, E.C. Thayer, M.P. Leckie, V.V. Braden, J.E. Depke, and M.V. Olson. 1993. Physical maps of the six smallest chromosomes of Saccharomyces cerevisiae at a resolution of 2.6 kilobase pairs. Genetics 134: 81-150.

Rose, M.D., P. Novick, J.H. Thomas, D. Botstein, and G.R. Fink. 1987. A Saccharomyces cerevisiae genomic plasmid bank based on a centromere-containing shuttle vector. Gene 60: $237-243$.

Rose, M.D., F. Winston, and P. Hieter. 1990. Methods in yeast genetics: A laboratory course manual. Cold Spring Harbor Laboratory Press, Cold Spring Harbor, New York.

Rothstein, R. 1991. Targeting, disruption, replacement, and allele rescue: integrative DNA transformation in yeast. In Methods in enzymology: Guide to yeast genetics and molecular biology (ed. C. Guthrie and G. Fink), vol. 194, pp. 281-301. Academic Press, San Diego, CA.

Sambrook, J., E.F. Fritsch, and T. Maniatis. 1989. Molecular cloning: A laboratory manual. Cold Spring Harbor Laboratory Press, Cold Spring Harbor, New York.

Sanger, F., S. Nicklen, and A.R. Coulson. 1977. DNA sequencing with chain terminating inhibitors. Proc. Natl. Acad. Sci. 74: 5463-5467.

Schiestl, R.H. and R.D. Gietz. 1989. High efficency transformation of intact yeast cells using single stranded nucleic acids as a carrier. Curr. Genet. 16: 339-346.

Sikorski, R.S. and P. Hieter. 1989. A system of shuttle vectors and yeast host strains designated for efficient manipulation of DNA in Saccharomyces cerevisiae. Genetics 122: 19-27.

Smith, V. and B.G. Barrell. 1991. Cloning of a yeast U1 snRNP $70 \mathrm{~K}$ protein homologue: Functional conservation of an RNA-binding domain between humans and yeast. EMBO $\%$. 10: $2627-2634$.

Struhl, K. 1987. Promoters, activator proteins and mechanism of transcriptional initiation in yeast. Cell 49: 295-297.

Thomas, B.J., and R. Rothstein. 1989. Elevated recombination rates in transciptionally active DNA. Cell 56: 619-630.

Urlaub, G., P.J. Mitchell, C.J. Ciudad, and L.A. Chasin. 1989. Nonsense mutations in the dihydrofolate reductase gene affect RNA processing. Mol. Cell. Biol. 9: 2868-2880.

White, T.J., N. Arnheim, and H.A. Erlich. 1989. The polymerase chain reaction. Trends Genet. 5: 185-189.

Whitfield, T.T., C.R. Sharpe, and C.C. Wylie. 1994. Nonsensemediated mRNA decay in Xenopus oocytes and embryos. Dev. Biol. 165: 731-734.

Winey, M. and M.R. Culbertson. 1988. Mutations affecting the tRNA-splicing endonuclease activity of Saccharomyces cerevisiae. Genetics 118: 607-617. 


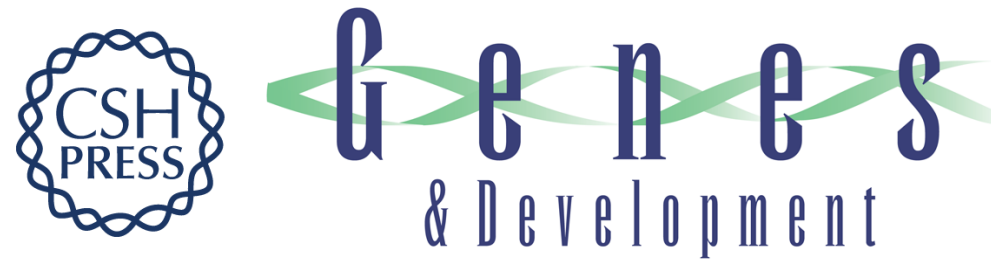

\section{Identification of a novel component of the nonsense-mediated mRNA decay pathway by use of an interacting protein screen.}

$\mathrm{F} \mathrm{He}$ and $\mathrm{A}$ Jacobson

Genes Dev. 1995, 9:

Access the most recent version at doi:10.1101/gad.9.4.437

References This article cites 67 articles, 34 of which can be accessed free at: http://genesdev.cshlp.org/content/9/4/437.full.html\#ref-list-1

License

Email Alerting

Service

Receive free email alerts when new articles cite this article - sign up in the box at the top right corner of the article or click here.

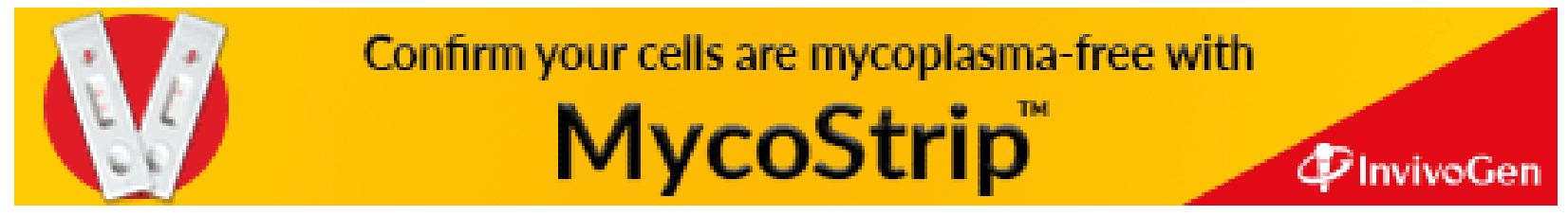

